\title{
Studien über die Verdauung der Kuhmilch und über die Mittel, ihre Verdaulichkeit zu erhöhen. \\ Von
}

\section{Prof. Dr. J. Uffelmann}

in Rostock.

Das Studium der Veränderungen, welchen die Kuhmilch bei dem Verdauungsacte unterliegt, ihrer Ausnutzung im Digestionstractus und der Methoden, ihre Verdaulichkeit zu erhöhen, hat ausser der rein wissenschaftlichen eine eminent-practische Bedeutung, da dies Nahrungsmittel bei der Ernährung gesunder und kranker Menschen eine so hervorragende Rolle spielt. Die Physiologie, die Pathologie und Therapie, ganz besonders aber die Hygiene des Kindes, welche trotz aller neu auftauchenden Surrogate doch immer wieder und mit Recht auf die Kuhmilch als den besten und billigsten Ersatz der Muttermilch zurückgreift, sie alle haben ein sehr hohes Interesse daran, über die so eben betonten Punkte möglichst genau aufgeklärt zu sein. Unser bisheriges Wissen bezüglich derselben ist aber ein voll befriedigendes nicht zu nennen, am wenigsten bezüglich der Methoden, welche die Erhöhung der Verdaulichkeit unseres Nahrungsmittels ins Auge fassen.

Aus diesem Grunde habe ich das gesammte Capitel von der Verdauung sowohl der Kuhmileh selbst, als verschiedener Zubereitungen derselben auf's Neue experimentell bearbeitet und lege hiemit meinen Fachgenossen die Ergebnisse der zu solchem Zwecke angestellten Untersuchungen vor. Dieselben betreffen:

I. Das Verhalten der Kuhmilch gegen verdünnte Salz- und verdünnte Milchsäure, sowie gegen künstlichen Magensaft;

II. Die Ausnutzung der Kuhmilch im Digestionstractus;

III. Die Verdaulichkeit gekochter Kuhmilch und der Buttermilch;

IV. Die Methoden, die Verdaulichkeit der Kuhmilch zu erhöhen.

E, Pflüger, Archiv f. Physlologie. Bd. XXIX. 


\section{Das Verhalten der Kuhmilch gegen verdïnnte Salz- und ver- dïnnte Milchsäure, sowie gegen künstlichen Magensaft.}

\section{a. Das Verhalten gegen verdünnte Salzsäure.}

Das Verhalten der frischen Kuhmilch gegen verdünnte Salzsäure ist ein höchst bemerkenswerthes. Bei einem bestimmten Mischungsverhältniss finden wir gar keine, bei einem anderen sehr dünne, bei einem anderen wiederum dickflockige, käsige Ausfällung. Ja, eine durch verdünnte Salzsäure hervorgerufene Ausfällung kann durch Zusatz einer gewissen Menge der nämlichen Säure wieder zum Verschwinden gebracht werden. Dass dieses Thatsachen sind, will ich durch folgende Versuche erweisen, die, sofern nicht etwas Anderes ausdrücklich bemerkt ist, durchweg mit einer 2\% Salzsäurelösung angestellt wurden.

1) Es werden 10,0 verdïnnte Salzsäure in einen graduirten Glascylinder gegossen und dann von einer frisch gemolkenen, amphoter reagirenden, nicht gekochten Milch successive Quanta von $1 / 2$ ccm zugesetzt, nach jedem Zusatz aber geschüttelt. Es entsteht zunächst eine einfach-trübe Flüssigkeit von fahler, grauer, nicht milchweisser Farbe; noch beim Zugiessen der letzten Tropfen des 7. ccm bleibt dies Verhältniss dasselbe. Sobald aber noch ein halber com zugegossen wird, beginnt obne merkbare Aenderung der Farbe eine äusserst zarte, fein staubartige Ausfäl. lung sich zu zeigen. Jeder Tropfen weiteren Zusatzes von Milch verstärkt die Ausfällung, die schon bei einem Gesammtzusatz von $8 \mathrm{ccm}$ Milch dickflockig erscheint und nunmehr sofort eine käsigweisse Farbe annimmt.

2) 10,0 verdünnte Salzsäure werden in der eben sub 1) angegebenen Weise successive mit $7,5 \mathrm{ccm}$ derselben Milch versetzt; es beginnt wiederum die feine, staubartige Ausfällung. Jetzt werden noch einige Tropfen Milch bis zur entschieden hervortretenden flockigen Gerinnung zugegossen, dann aber 5,0 der nämlichen $2 \%$ Salzsäure beigemischt und nun geschüttelt. In wenigen Sekunden verschwindet die milchweisse Farbe, die fahle, molkenartige tritt an die Stelle, und die Gerinnung macht einer einfachen Trübung Platz. Von Flocken ist nicht die geringste Spur mehr zu entdecken; ja auch nicht einmal von einer staubartig feinen Ausfällung lässt sich noch etwas wahrnehmen.

3) 10,0 verdünnte Salzsäure werden in der sub 1) angegebenen Weise successive mit $8,5 \mathrm{~cm}$ einer schwach alkalisch reagirenden, ungekochten Milch 
versetzt. Es zeigt sich eben beginnende staubförmige Ansfällung, die auf Zusatz von 2,0 verdünnter Salzsäure wieder schwindet.

4) Ziemlich stark säuerlich reagirende Kuhmilch (18 Stunden alt) wird ebenfalls in Mengen von $1 / 2 \mathrm{ccm}$ einem Quantum von 10,0 verdünnter Salzsäure unter Schütteln zugemischt. In dem Augenblicke, wo die letzten Tropfen des 7. ccm Milch eingegossen werden, fängt eine staubförmige Ausfällung an, sich zu zeigen. Die Hinzufügung noch eines halben ccm Milch ruft flockige Ausfällung hervor.

Es bedarf hiernach einer besonderen Aufmerksamkeit, um dasjenige Mischungsverhältniss, bei welchem eben eine staubförmige Ausfällung Statt hat, zu finden. Giesst man ein wenig, nur einige Tropfen zuviel Milch hinza, so zeigt sich die flockige Gerinnung, und zwar nun auf einmal in der ganzen Flüssigkeit. Das Mischungsverhältniss ist, wie auch die Versuche lehren, nicht immer gleich. Reagirt die Milch amphoter, so kann man rechnen, dass auf $10 \mathrm{ccm} \mathrm{2 \%}$ Salzsäure $7-8 \mathrm{cem}$ Milch unter stetem Schütteln zugesetzt werden müssen, wenn der Beginn der Ausfällung in Staubform sich zeigen soll. Ich habe aber auch schon Milch von amphoterer Reaction untersucht, von der $10 \mathrm{ccm}$, und andere, von der nur $6 \mathrm{ccm}$ zuzusetzen waren, bis jene Erscheinung eintrat. Von Einfluss ist zweifellos der Gehalt an Wasser und an Salzen. Schwach säuerliche Reaction bedingt kaum merkbaren Unterschied, wohl aber eine entschieden alcalische.

Wichtiger noch, als die Thatsache der anfänglich staubförmigen, aber durch den geringsten Mehrzusatz von Mileh alsbald flockig werdenden Gerinnung ist die andere, aus obigen Versuchen sich ergebende, dass die durch verdünnte Salzsäure hervorgerufene Ausfällung durch ein Plus der nämlichen verdünnten Säure wieder verschwindet. Letztere vermag also zu fällen und das Gefällte wieder zu lösen bei völlig gleichbleibender Concentration der Säure.

Das hier Vorgetragene ist nicht völlig neu. Schon Fleischmann erwähnt in seiner Abhandlung: „Ueber Ernährung und Körperwägungen der Neugeborenen und Säuglinge" 1875 S. 40, dass schwache Lösungen von Salzsäure unter gewissen Verhältnissen in der Kuhmilch eine staubförmige Ausfällung hervorrufen. Davon, dass die nämliche Säure auch flockige Coagula wieder zu lösen vermöge, sagt er aber gar Nichts. Jacobi gedenkt neuer- 
dings in dem Capitel: Pflege und Ernährung des Kindes (Gerhardts Handbuch der Kinderkrankheiten. 2. Aufl. I. 2. S. 99) einer Mischung von Milch und Salzsäure, die, von Rudisch angegeben, frei von Gerinnsel sei und diätetisch sich sebr bewährt habe. Diese Mischung soll sein: Salzsäure (verdünnte?) 1, Wasser 250,0, frische Milch 500,0. Mehr Salzsäure dürfe nicht zugesetzt werden, weil sonst Gerinnung eintrete. Jacobi betont aber nur den diätetischen Werth and erwähnt nicht etwaiger Veränderungen, die durch solche Zumischung in dem Aussehen oder der sonstigen Beschaffenheit der Milch erzeugt seien.

Von der Angabe Fleischmann's ist ïbrigens wenig Notiz genommen worden. Auch Biedert hat sie ganz iibersehen; er sagt von der verdünnten $(4 \%$ ) Salzsäure nur, dass sie die Kuhmilch flockig fälle. Dies ist richtig und zugleich falsch. Auch für $4 \%$ Salzsäure giebt es ein Verhältniss, in welchem Kuhmileh nicht flockig, sondern staubartig gefällt oder gar nicht gefällt wird. In der Regel wird man auf 10,0 der $4 \%$ Salzsäure 14$14,5 \mathrm{ccm}$ frischer amphoter reagirender Kuhmilch zusetzen können, ehe eine staubartige Ausfällung sich zeigt, wenn man nur sehüttelt. Giesst man dann noch 1 ecm Mileh mehr hinzu, so tritt flockige Ausfällung ein, und giesst man dann wieder $4 \%$ Salzsäure zu, so löst sich auch wieder das Gerinnsel beim Schütteln.

Bei Verwendung von nur $1 \%$ Salzsäure lässt sich die gleiche Erscheinung constatiren. Auf 10,0 derselben wird man meistens 3,9-4 ccm Milch zusetzen können, ehe feine Ausfällung sich zeigt. Man darf deshalb nicht sagen, dass verdünnte Salzsäure unter allen Umständen eine flockige Gerinnung der Kuhmilch zu Wege bringt.

Bisher war immer nur die Rede vom Verhalten der Kullmilch bei allmählichem Zusatze derselben zur verdünnten Salzsäure. Sehen wir nunmehr, welches Ergebniss der entgegengesetzte Versuch, nämlich der Zusatz steigender Mengen von verdünnter Salzsäure zur Milch hat.

1) Giesst man zu $5 \mathrm{ccm}$ amphoter rełgirender Kuhmilch 1,0 einer $2 \%$ Salzsäure, so entsteht keine Ausfällung, nicht einmal staubartige. Erhitzt man die Mischung aber zum Kochen, so gerinnt sie sofort.

2) Giesst man zu $5 \mathrm{ccm}$ eben soleher amphoter reagirender Milch $2,5 \mathrm{ccm}$ einer $2 \%$ Salzsäure, so entsteht bei gewöhnlicher Temperatur noch gar 
keine Ausfällung, wohl aber, wenn man die Masse kurze Zeit einer Verdau ungswärme (von $40^{\circ}$ C.) aussetzt.

3) Giesst man zu $5 \mathrm{ccm}$ der gleichen Milch zuerst 2,5 ccm einer $2 \%$ Salzsäure, und dann allmählich mehr der letzteren, so tritt bei einem Zusatze von 2,8-3,0 dünne Gerinnung, bei einem Zusatze von 4,0 derbe Gerinnung ein. Steigert man dann den Säurezusatz, so beginnen, jedenfalls wenn geschüttelt wird, die Gerinnsel sich wieder zu lösen. Sind im ganzen etwa 8,0 der $2 \%$ Säure zugesetzt, so erscheint die Flüssigkeit molkenartig, nicht mehr milchweiss und ohne alle Gerinnsel. Schüttelt man nicht, so bleiben am Boden des Gefässes einzelne Coagula unaufgelöst. Kocht man jetzt, so entsteht keine Gerinnung.

Es geben also $5 \mathrm{ccm}$ einer amphoter reagirenden Kuhmilch:

1) mit $1,0-2,5 \mathrm{ccm}$ einer $2 \%$ Salzsäure nicht bei gewöhnlicher Temperatur, wohl aber in der Siedhitze, bzw. in der Verdauungswärme, Gerinnung;

2) mit 4,0 ccm einer $2 \%$ Salzsäure bei gewöhnlicher Temperatur derbe Gerinnung;

3) mit $8,0 \mathrm{ccm}$ einer $2 \%$ Salzsäure hinreichend geschtittelt weder bei gewöhnlicher Temperatur, noch bei Siedhitze Gerinnung.

Stellt man Kuhmilch, nachdem man sie unter Schütteln mit soviel verd. Salzsäure versetzte, dass die entstehenden Gerinnsel sich ganz wieder lösen, also beispielsweise $25 \mathrm{ccm}$ frischer Milch mit 35,0 cem der 2\% Salzsäure, bei gewöhnlicher Stubentemperatur, selbst in offenem Gefässe, hin, so gerinnt sie nicht mehr, wird demnach auch in dieser Beziehung der Frauenmilch gleich, welche bekanntlich bei längerem Stehen nicht mehr coagulirt, auch wenn sie sauer wird. Ich habe solche Kuhmilch während des verflossenen Winters in meinem Auditorium bei einer durchschnittlichen Temperatur von $18-19^{\circ} \mathrm{C}$, und auch noch während des laufenden Sommers bei viel höherer Wärme wochenlang stehen gehabt, ohne dass sie irgend eine andere Veränderung kund gab, als dass sich auf ihr eine Rahmschicht bildete. Augenscheinlich modificirt die verdünnte Salzsäure mit den vorhandenen Fermenten das Proteïn der Mileh. Eine nähere Untersuchung ergibt die Richtigkeit dieser Annahme.

Wenn man nämlich obige Mischung, nachdem sie 24 bis 30 Stunden hindurch gestanden, mit etwas concentrirter Salpetersäure behandelt, so entsteht eine käsig flockige Ausfällung. Filtrirt 
man nun, so erhält man ein ganz klares Filtrat, welches, nachdem man die Säure bis fast zur Neutralisation abstumpfte,

1) beim Kochen nur wenig sich trübt,

2) bei völliger Neutralisation mitunter gar nicht, mitunter etwas sich trübt, und welches

3) nach Abfiltrirung des durch Kochen resp. Neutralisirung etwa entstandenen Niederschlags mit absolutem Alkohol, mit Tannin, mit Phosphorwolframsäure starke Ausfällung zeigt, bei Zusatz von Kalilauge und verdiunnter Kupfervitriollösung schön roth oder violett sich färbt.

Das erste, nach Zusatz conc. Säure gewonnene Filtrat enthält also Albumin in geringer Menge, Nentralisationspräcipität in geringer Menge oder gar nicht, und Pepton in grösserer Menge. Dass letzteres spurenweise anch in frischer Milch gefunden wird, ist mir wohl bekannt; in der von mir angegebenen Mischung aber zeigt es sich in so beträchtlicher Quantität, dass es erst nachträglich sich gebildet haben muss.

Ich habe die Menge des Peptons mehrfach genau bestimmt und in vier Fällen folgende Werthe gefunden:

1) in $27,5 \mathrm{ccm}$ Milch $+35,0$ Salzsäure von $2 \%$ nach 24 St. $=$ 0,317 Pepton.

2) in $50 \mathrm{ecm}$ Milch $+65,0$ Salzsäure von $2 \%$ nach 18 St. $=$ 0,498 Pepton.

3) in $25 \mathrm{ecm}$ Milch $+33,5$ Salzsäure von $2 \%$ nach 24 St. $=$ 0,301 Pepton.

4) in $50 \mathrm{ccm}$ Milch $+65,0$ Salzsäure von $2 \%$ nach 24 St. $=$ 0,570 Pepton.

Die Milch war jedesmal der nämlichen Quelle entnommen und enthielt 4,78\% Proteïnsubstanz. Von letzteren wurden demnach $20 \%$ bis gegen $25 \%$ in Pepton übergeführt, was sicherlich sehr beachtenswerth ist. Ein längeres Stehenlassen der Mischung befördert diese Ueberführung noch ein wenig, doch bleibt śtets die grössere Menge des Proteïns unpeptonisirt.

Wenn man solche unfiltrirte Mischung von Milch und Salzsäure nach etwa vierundzwanzigstündigem Stehen vorsichtig mit einer Lösung von kohlensaurem Natron versetzt, so beginnt frühzeitig, lange bevor die Abstumpfung der Säure eine vollständige ist, eine flockige Ausfällung. Fährt man dann mit dem Zugiessen der nämlichen Lösung fort, so verschwinden die Flocken 
wieder und zwar sobald man die Abstumpfung gerade vollendet oder nahezu vollendet. Die dann resultirende Mischung hat wieder Milchgeschmack, auch das Aussehen verdünnter Milch. Verdünnte Salzsäure von $2 \%$ und $4 \%$ ruft in ihr noch immer, wenn ein bestimmtes Verhältniss gewählt wird, flockige Ausfällung hervor, doch ist die letztere entschieden weniger consistent, als in der mit Wasser verdünnten Milch.

Zweifellos werden sich sowohl die einfache ebenbesprochene Mischung von Kahmilch mit verdünnter Salzsäure, als auch die neutralisirte Mischung diätetisch sehr gut verwerthen lassen. Ich selbst werde in allernächster Zeit Versuche damit anstellen und ersuche Fachgenossen, ein Gleiches zu thun, etwa in fieberhaften Erkrankungen, in denen unverdiunnte oder mit Wasser verdiunnte Milch so oft nicht vertragen wird.

Man kann die salzsaure Mischung auch noch in anderer Weise verwerthen. Hat man sie so bereitet, dass feine staubartige Ausfällung nicht ganz in Erscheinung trat, oder, nachdem sie erschienen, durch ein geringes Plus der verdünnten Säure wieder schwand, so bringt ein Zusatz gewöhnlicher Milch sofort eine flockige Ausfällung hervor. Filtrirt man nun, so gewinnt man ein schwach saures Filtrat, das neben dem Zucker und den Salzen eine Lösung von Eiweiss und Pepton enthält, angenehm schmeckt, auch sehr leicht verdaulich ist. Es scheint mir empfehlenswerth besonders da, wo Fett nicht verdaut werden kann. Setzt man diesem Filtrate Pepsin zu und stellt man es dann in eine gleichmässige Temperatur von $40^{\circ}$, so zeigen sich nur sehr lockere, kleinste Gerinnselchen von grauer Farbe.

\section{b. Das Verhalten der Kuhmilch gegen verdünnte Milchsäure.}

Das Verhalten der Kuhmilch gegen verdünnte Milchsäure ist ein nicht unerheblich anderes, als gegen verdünnte Salzsäure, wie sich aus folgenden Versuchen ergibt.

1) Es werden $10 \mathrm{ccm}$ einer $2 \%$ Milchsäurelösung in einem graduirten Glascylinder mit amphoter reagirender Kuhmilch tropfenweise unter Schütteln versetzt. In dem Augenblicke, in welchem $1,8 \mathrm{ccm}$ Milch zugegossen sind, beginnt die Ausfällung, die sehr dünn, schon bei Zusatz von einigen weiteren Tropfen Milch dickflockig erscheint. Nunmehr werden wiederum $1 \mathrm{ccm}$, dann 
noch $1 \mathrm{ccm}$, schliesslich im Ganzen $5 \mathrm{ccm}$ der verdünnten Milchsäure unter Schütteln zugesetzt. Die Flocken werden feiner, lösen sich jedoch nicht auf.

2) Es werden 10 cem einer $2 \%$ Milchsäurelösung in der eben sub 1) angegebenen Weise mit der nämlichen Milch vermischt, bis die erste Ausfällung sich zeigt. Es sind dazu wieder $1,8 \mathrm{ccm}$ Milch verbraucht. Dann werden $5 \mathrm{ccm}$ einer $2 \%$ Salzsäurelösung zugegossen und nun geschüttelt. In einer Minute sind die Flocken verschwunden.

3) Es werden $10 \mathrm{ccm}$ einer nur 1\% Milchsäurelösung unter Schütteln mit allmählich gesteigerten Mengen Kuhmilch versetzt. In dem Augenblicke, wo $1,2 \mathrm{ccm}$ von letzterer verbraucht sind, zeigt sich dünnflockige, wo $1,5 \mathrm{ccm}$ verbraucht sind, dickflockige Gerinnung.

Die Milchsäure erzeugt demnach gleichfalls bald eine dïnnere, bald eine dickere Ausfällung; aber sie vermag die Gerinnsel nicht völlig wieder zu lösen. Wesentlich verschieden ist bei ganz gleichem Gehalt einer Flüssigkeit an Milch- bzw. Salzsäure die Menge des Milchzusatzes, welche erforderlich ist, damit der Beginn einer Ausfällung zu Tage tritt. Es verhält sich 0,2 Milchsäure zu $18 \mathrm{ccm}$ Milch, wie 0,2 Salzsäure zu $75 \mathrm{ccm}$ Milch, wenn ein Säuregehalt von $2 \%$ angenommen wird.

Nicht uninteressant ist es zu erfahren, in welcher Weise eine Lösung wirkt, welche Milch- and Salzsäure zugleich enthält. Ich verwandte zur Prüfung eine Lösung, die in $100 \mathrm{ccm}$ destillirten Wassers $=0,06$ Salzsäure und 0,20 Milchsäure, also 0,26 Säure hatte. Setzte ich zu $10 \mathrm{ccm}$ dieser Lösung von amphoter reagirender Kuhmilch 4,5 ccm, so zeigte sich Ausfällung, die bei Zugabe von weiteren drei Tropfen Milch alsbald dickflockig wurde. Da in $10 \mathrm{ccm}$ einer $2 \%$ Milchsäurelösung, die nicht zugleich Salzsäure enthält, schon $1,8 \mathrm{~cm}$ Milch Gerinnung erfährt, so erkennt man aus obigem Resultat sofort die bedeutsame Einwirkung der Salzsäure selbst in sehr starker Verdünnung.

Ist die letztgenannte Säure in etwas stärkerer Concentration anwesend, so tritt die Wirkung der Milchsäure sehr erheblich in den Hintergrund oder schwindet ganz. Wenn man z. B. zu einer Mischung von $9 \mathrm{ccm}$ einer $2 \%$ Salzsäure $+1 \mathrm{ecm}$ einer $1 \%$ Milchsäure amphoter reagirende Kuhmilch langsam und unter Schütteln hinzusetzt, so wird man beim Zugiessen von etwa $7,25 \mathrm{cem}$ Milch den ersten Anfang einer Ausfällung beobachten. In diesem Falle ist also der Einfluss der Milchsäure fast Null, da zu $10 \mathrm{ccm}$ 
einer 2\% Salzsäure in der Regel 7,5 $\mathrm{ccm}$ Milch gesetzt werden, bis Gerinnung eintritt.

Aus den eben mitgetheilten Versuchen erbellt aber ohne Weiteres, dass das gegenseitige Verhältniss der beiden Säuren, bzw. des Grades ihrer Concentration zu einander von Bedeutung fur die Veränderungen sein wird, welche die Kuhmileh im Magen erleidet. Eine starke Prävalenz der Milchsäure bei fast fehlender Salzsäure muss ganz anders wirken, als eine Prävalenz der Salzsäure bei schwach vorhandener Milchsäure. Desshalb dürfte das soeben Vorgetragene auch die Pathologie interessiren.

\section{c. Das Verhalten der Kuhmilch bei künstlicher Verdaung.}

Die Versuche künstlicher Verdaung von Kuhmilch habe ich angestellt a) mit einer Flüssigkeit, welche $2 \%$ Salzsäure und $0,8-1 \%$ wirksames Pepsin enthielt, b) mit einer solchen, welche $1,5 \%$ Salzsäure, $0,5 \%$ Milchsäure und $0,8-1 \%$ Pepsin enthielt. Verwandt wurde nur frische, amphoter reagirende Kuhmilch; ïber die Versuche mit gekochter Milch wird weiter unten berichtet werden.

a) Verdaungsversuche mit Salzsäure und Pepsin.

1) Es werden $20 \mathrm{ccm} K u$ hmilch mit $15 \mathrm{ccm}$ Verdauungsflüssigkeit a geschüttelt und in einem Glasgefässe mit weiter Oeffnung einer gleichbleibenden Wärme von $40^{\circ}$ C. ausgesetzt, ohne dass weiter geschüttelt wird. In der Mischung zeigen sich zu Anfang dickflockige Gerinnsel. Sehon nach 10 Min. haben sich diese zu einem weissen, käsigen, $1,5 \mathrm{~cm}$ dicken Klumpen vereinigt, der eine obere, glatte Fläche mit einer Delle und eine untere zottige, convexe Fläche hat. Im weiteren Verlaufe der Digestion verkleinert sich der Klumpen, dessen Delle dabei immer tiefer wird. Nachdem eine Stunde seit dem Beginn des Versuchs verstrichen ist, ist der Klumpen noch eine Scheibe von $0,5 \mathrm{~cm}$ Dicke.

Die Flüssigkeit, auf der sie schwimmt, ist molkenartig, schwach trübe und schmeckt bitter; auf dem Boden finden sich noch einzelne kleinere, käsigweisse Gerinnsel, die vielleicht von dem grossen Coagulum sich losgelöst haben.

Weiterhin verändert sich das Aussehen sehr wenig; die Scheibe wird noch etwas dünner, verschwindet aber keineswegs ganz. Die umgebende Flüssigkeit bleibt molkenartig und wird noch bitterer im Geschmacke.

Untersucht man Theile der persistirenden Scheibe oder Theile der kleinen Gerinnsel am Bodén, so findet man in ihnen zahllose Fetttröpfchen 
dicht aneinander gruppirt, findet aber auch eigenthümliche hyaline Scheiben von verschiedener Grösse und verschiedenen Contouren, fast immer mit zackigen Rändern und immer mit rundlichen oder elliptischen Oeffnungen. Letztere sind augenscheinlich die Stellen, an denen Fettiröpfchen ihre Lage hatten, während die hyalinen Scheiben aus Eiweissmasse bestehen, da sie in verdünnter Kali- bezw. Natronlange leicht sich lösen, in concentrirter Schwefelsäure opak werden.

Die mikroskopische Untersuchung der Flüssigkeit zeigt neben mässig zahlreichen Coccen und Stäbchen viele Fetttröpfchen. Diese sind meistens isolirt: doch kommen auch noch kleine Gruppen derselben vor, die durch Druck auf das Deckgläschen nicht vomeinander entfernt werden, also noch durch eine bindende Masse vereinigt sind.

Die chemische Untersuchung ergab Folgendes:

Schüttelte ich die ganze, der Verdauung ausgesetzte Masse mit Aether, so nahm derselbe leicht Fett in sich auf. Dies ist eine auf die stattgehabte Digestion zurïckzuführende Veränderung, da unverdaute Kuhmilch an Aether nur schwer und wenig abgiebt.

Filtrirte ich nach vollzogener Entfettung, so erhielt ich ein völlig klares Filtrat. Dieses

trübte sich beim Kochen nur wenig,

trübte sich bei Neutralisirung und bei Zusatz von Ferrocyankaliumlösung nebst Essigsäure ebenfalls nur wenig.

Die nach Abfiltrirung der durch Kochen, bezw. Neutralisirung entstandenen Niederschläge zurückbleibende Flüssigkeit gab mit Tannin, Phosphorwolframsäure, absolutem Alkohol sehr starken Niederschlag.

Hiernach enthielt die der Verdauung ausgesetzte Masse in der molkenartigen Flüssigkeit geringe Mengen unverdauten Eiweisses und Neutralisationspräcipitats, grosse Mengen Pepton.

Was nach stattgehabter Entfettung der verdauten Masse auf dem Filter zurückblieb; war eine käsigweisse Substanz, die in verdünnter Natronlauge sich löste und aus derselben durch verdünnte Essigsäure, sowie durch Tannin gefällt wurde. Veraschte ich diese Caseïnmasse, so liess sich Kalk in ziemlich erheblicher Menge nachweisen.

2) Zu 20,0 einer $2 \%$ Salzsäure werden successive unter Schütteln $20 \mathrm{ccm}$ amphoter reagirender Kuhmilch hinzugegossen und dann ein Quantum von 0,2 Pepsin beigemengt. Die Flüssigkeit, in der sich alsbald eine derbflockige Gerinnung kundgiebt, wird noch einmal gehörig geschüttelt und dann einer gleichbleibenden Wärme von $40^{\circ} \mathrm{C}$. ausgesetzt.

Nach 10 Minaten finde ich die käsigweissen, grossen Flocken auf dem Boden des Glases sehr locker aneinander liegend, doch nicht zu einem einzigen umfangreichen Coagulum vereinigt, wie beim zuletzt beschriebenen Versuche 1. Ueber der Flockenmasse befindet sich eine fast wasserklare Flüssigkeit, in der einzelne kleine, fetzenartige, weisse Flocken schwimmen. 
Nach weiteren 10 Minuten ist das Bild fast das nämliche. Am Ende einer Stunde der Verdauung sehe ich noch immer sehr locker vereinigte, käsig-weisse Flocken, aber die Gesammtmasse derselben ist ungleich geringer geworden als vorher und macht nur etwa den vierten Theil der anfänglichen aus. Ueber ihr steht eine fast klare, kaum gefärbte Flüssigkeit, auf der sich eine zarte weissgelbliche Rahmschicht befindet, und in der kleine weisse Körnchen und Fetzen schwimmen. Schüttele ich, so vertheilen sich die locker vereinigten, am Boden liegenden Flocken in der Flüssigkeit, um aber nach wenigen Minuten wieder abwärts zu sinken und ein ähnliches Bild wie vorher darzubieten.

Im weiteren Verlaufe der Verdauung tritt eine wesentliche Aenderung nicht mehr ein. Es verbleiben auf dem Boden die erwähnten käsigweissen, locker aneinander liegenden Flocken in nahezu gleicher Menge.

Die Flüssigkeit lässt sich leicht filtriren und giebt ein absolut klares Filtrat, das beim Kochen sich wenig, bei Zusatz von Ferrocyankalium und Essigsäure etwas mehr sich trübt, bei Zusatz von Tannin aber ungemein starken Niederschlag zeigt.

Die Versuche 1 und 2 ergaben also nahezu Gleiches; nur war in 1 ein derbes Coagulum, in 2 eine lockere Auseinanderlagerung von Flocken vorhanden.

3) Es werden zu $25 \mathrm{ccm}$ einer $2 \%$ Salzsäure successive unter Schütteln fast $20 \mathrm{~cm}$ amphoter reagirender Kuhmilch hinzugesetzt. Feine, staubartige Ausfällung beginnt sich zu zeigen. Nunmehr füge ich 0,20 Pepsin hinzu, schüttele noch einmal und setze die Flüssigkeit einer gleichbleibenden Wärme von $40^{\circ} \mathrm{C}$. aus.

Nach 10 Minuten werden die in Staubform vorhandenen Ausfällungen etwas umfangreicher, und bilden kleine, äusserst lockere Flöckchen von grauer Farbe. Käsigweisse Gerinnselchen zeigen sich nirgends; auch tritt an keiner Stelle eine Vereinigung von Fiöckchen zu einem Coagulum derberer Art ein. Dies bleibt so im weiteren Verlaufe der Verdauung, so dass also das Bild ein völlig anderes ist, als im Versuch 1.

Nachdem $2 \frac{1}{2}$ Stunden verstrichen sind, finde ich eine molkenartige, trübe Flüssigkeit, auf deren Oberfläche sich zahlreiche, kleine Fettaugen zeigen und in der noch zahlreiche lockere Gerinnselchen suspendirt sind. Umfangreichere Fetzen oder Klumpen giebt es nicht.

Aether nimmt Fett sehr leicht auf, wie in Versuch 1.

Die Filtration der entfetteten Flüssigkeit vollzieht sich sehr rasch, liefert auch ein völlig klares Filtrat, sowie einen sehr geringfügigen Rückstand auf dem Filter.

Das Filtrat trübt sich beim Kochen fast gar nicht;

trübt sich bei Zusatz von Ferrocyankaliumlösung und Essigsäure nicht mehr, als das Filtrat in Versuch 1;

trübt sich aber bei erfolgender Neutralisation ziemlich bedeutend und zeigt mit Tannin eine sehr starke Ausfäliung. 
4) $\mathrm{Zu} 25,0$ einer $2 \%$ Salzsäure werden successive unter Schütteln $18 \mathrm{ccm}$ amphoter reagirender Kuhmilch gesetzt. Es findet keine Ausfällung statt, nicht einmal staubartige. $\mathrm{Zu}$ jener Flüssigkeit bringe ich 0,20 Pepsin und setze sie dann einer gleichbleibenden Wärme von $40^{\circ} \mathrm{C}$. aus. Nach 8-9 Minuten zeigen sich feine, äusserst lockere Flöckchen inmitten der molkenartigen Flïssigkeit.

Im weiteren Verlaufe der Digestion nehmen die Flöckchen ein wenig an Umfang zu, bilden aber keine derben Conglomerate, keine käsigweissen Gerinnsel. Noch später ist das Aussehen der Flüssigkeit genau wie in 3), ebenso das chemische Verhalten des Filtrates.

5) Zu 20,0 einer Lösung, die 1,5\% Salzsäure und 0,5\% Milchsäure enthält, werden $25 \mathrm{ccm}$ amphoter reagirender Kuhmilch hinzugesetzt, 0,2 Pepsin beigemengt und die Masse einer Verdauungswärme von $40^{\circ} \mathrm{C}$. ausgesetzt. Gleich beim Zugiessen der Säurelösung entsteht eine derbflockige Ausfällung. Nach 8 Minuten finde ich in dem Gefässe ein $1,5 \mathrm{~cm}$ dickes weisskäsiges Coagulum, das unten dem Boden aufliegt, oben mit concaver Fläche etwa $1 \mathrm{~cm}$ unter der Oberfläche der molkenartigen Flüssigkeit sich befindet, welche den übrigen Inhalt ausmacht. Im weiteren Verlaufe der Verdauung bildet sich auf der Flüssigkeit eine zarte, graugelbliche Fettschicht. Das Coagulum wird allmählich weniger dick und weniger umfangreich, auch lockerer. Zwei volle Stunden nach Beginn des Versuchs ist es noch etwa $0,5 \mathrm{~cm}$ dick, wie Käsequarg aussehend und verändert sich weiterhin nicht mehr wesentlich.

6) $\mathrm{Zu}$ 20,0 einer Lösung von 1,5\% Salzsäure und $1 \%$ Milchsäure wird 0,2 Pepsin und dann ein Quantum von $15 \mathrm{~cm}$ amphoter reagirender Kuhmilch zugesetzt. Es zeigt sich nach vorgenommener Mischung eine staubartige Ausfällung in molkenartig aussehender Flüssigkeit. Die Masse wird nunmehr einer gleichbleibenden Wärme von $40^{\circ} \mathrm{C}$. ausgesetzt. Schon nach $6^{1} / 2$ Minuten erscheinen die Gerinnsel umfangreicher als anfänglich, aber ebenso locker uud zart. Von einer Bildung käsigweisser Flocken und einer Vereinigung derselben zu einem Klumpen, wie in Versuch 5, ist nichts zu sehen. Nach Ablauf einer Viertelstunde bietet sich dasselbe Bild dar. Späterhin, nach weiteren 60 Minuten, finde ich auf der Oberfläche der noch immer molkenartig aussehenden Flüssigkeit eine dünne Rahmschicht, die Flüssigkeit selbst stark trübe. Die Gerinnsel in ihr sind sparsamer und kleiner geworden als sie vorher waren; Flocken, Klümpchen fehlen auch jetzt vollständig. Zwei Stunden nach Beginn des Versuchs ist das Bild dasselbe; desgleichen nach weiteren zwei Stunden.

Aus allen diesen Versuchen erhellt zunächst wiederum der sehr bedeutsame Einfluss, welchen das Mischungsverhältniss von Milch und verdünnter Salzsäure auf den ganzen Ablauf der Ver- 
dauung dieses Nahrungsmittels ausübt. Ist soviel verdünnte Salzsäure vorhanden, dass in der Kälte keine oder doch nur eine feine staubartige Ausfällung zu Tage tritt, so bilden sich auch während der Digestion unter allen Umständen nur ganz lockere, graue Flöckchen, nicht käsig weisse und nicht sich zusammenballende Flocken. Es gibt demnach ein Mischungsverhältniss, bei welchem während der ganzen Verdauung Kuhmilch genau so sich verändert, wie Frauenmilch, bei der ja gerade die digestorische Gerinnung in dünne, leichte Flöckchen als charakteristisch bis jetzt stets hervorgehoben worden ist. Diese Thatsache, dass das Vorhandensein einer bestimmten Menge verdïnnter Säure im Verhältniss zur Menge der Kuhmileh die Verdauung der letzteren in dem eben bezeichneten Sinne modificirt, ist ebenso feststehend, wie practisch belangreich, und dïrfte wohl anch die Anschauungen über die Natur das Kuhcaseïn in Etwas abändern.

Wenn aber Milch und verdünnte Säure in solchem Verhältniss stehen, dass in der Kälte eine Bildung derber, käsig weisser Flocken eintritt (z. B. 5 Th. Milch zu etwa 4 Th. einer 2\% Salzsäure), so bleiben diese Flocken auch während der Verdaunng, ballen sich, wenn nicht fleissig geschüttelt wird, zu grösseren Gerinnseln zusammen und setzen dann der Peptonisirung natürlich bedeutenderen Widerstand entgegen. Ist so wenig Säure vorhanden, dass in der Kälte gar keine Ausfällung erfolgt, z. B. auf $10 \mathrm{ccm}$ Milch nur 3 bis $4 \mathrm{ccm}$ einer $2 \%$ Salzsäure, also 0,006 bis 0,008 der letzteren, so entsteht, was a uf manche pathologische Beobachtung ein aufklärendes Licht wirft, nach Zufügung von Pepsin in der Wärme ungemein rasch eine dicke, klumpige Gerinnung, welche die Peptonisirnng schwer behindert. Sie ist so derb, wie nur je bei Labzusatz, und wird auch dann noch als solche beobachtet, wenn man die Milch zuvor mit dem Doppelten oder Dreifachen ihres Volumens Wasser verdünnte.

Das Vorhandensein kleiner Mengen Milchsäure neben grösseren Mengen Salzsäure übt keinen bemerkenswerthen Einfluss auf die Verdauung der Milch. Prävalirt aber die Milchsäure, so tritt etwas derbere Gerinnung und, wie es scheint, auch eine Verlangsamung der Peptonisirung ein.

Rasches Zugiessen der Milch zur Verdauungsfliissigkeit bedingt regelmässig, wenn überhaupt, eine derbere Gerinnung, als langsames. - Auch dies ist diätetisch gewiss von Bedeutung. 
Fleissiges Schütteln hat zur Folge, dass die derberen Flocken kleiner werden, dass grosse, zusammenhängende Coagula sich nicht bilden.

Nicht ohne Interesse dürfte es sein, mit den Ergebnissen der Versuche künstlicher Verdaung das Resultat von Beobachtungen natürlicher Verdauung der Mileh zu vergleichen. Wenn dem gastrotomirten Knaben Kröger ${ }^{1}$ ) ungekochte Kuhmilch eingeführt wurde, so konnte mindestens noch eine Viertelstunde nachher eine völlig milchige Flüssigkeit zurückgewonnen werden. Doch fanden sich in dieser schon nach Ablauf von 10 Minuten Gerinnselchen. Mit längerer Dauer der Digestion nahmen letztere an Consistenz und Umfang za. War eine halbe Stunde nach der Einführung der Milch verstrichen, so erhielt ich niemals eine milchige Flüssigkeit, sondern eine wässerig molkenartige zurück, die trübe war, aber klar filtrirte. Mit ihr gelangten auch regelmässig ziemlich voluminöse Coagula nach aussen, die das bekannte milchig weisse Aussehen hatten, so dass alsdann eine vollständige Scheidung der Milch zu constatiren war. Sehr schön war dies zu sehen, wenn der Knabe nach dem Genusse auf dem Rücken liegen blieb, und ich nun in den Gummischlauch der Fistel einen Glascylinder einsetzte. Es erschien dann in letzterem eine rein wässerige Flüssigkeit, die auf- und niederwogte. Kam der Knabe dabei zufällig in's Husten oder in's Würgen, so stürzten mit der Flüssigkeit auch jene Coagula hervor, die vorher sicherlich nach der hinteren Magenwand sich hingelagert hatten. Waren $5 / 4$ Stunden nach Einführung der Milch verflossen, so trat beim Oeffnen des Gummischlauches nur noch sehr wenig Flüssigkeit, fast lediglich käsigweisses, dickes Gerinnsel hervor.

Dass diese Vorgänge voll der Norm entsprachen, kann ich allerdings nicht erweisen; denn der Gastrotomirte hatte kein absolut physiologisches Verdauungsvermögen, zum Mindesten nicht in der Zeit, als diese Beobachtungen an ihm angestellt wurden. Nach Wahrnehmungen an gesunden Säuglingen, die bekanntlich leicht und oft erbrechen, darf wohl behauptet werden, dass der Regel nach eine Scheidung der von ihnen genossenen Kuhmilch in eine molkenartige Flïssigkeit und in Gerinnsel schon mit

1) Siehe meine Abhandlung über denselben im Deutschen Archiv für klin. Medicin. 1877. Bd. XX. p. 567. 
15-18 Minuten nach der Ingestion sich vollzieht, also wohl etwas früher, als bei dem Gastrotomirten der Fall war. Es ist freilich auch möglich, dass das Alter Einfluss übt, weil wahrscheinlich die Concentration der Säure bei Säuglingen eine andere ist, als bei älteren Personen. In Krankheiten von Kindern beobachtet man mitunter sehon 8-10 Minuten nach dem Genusse der Kuhmilch ein Erbrechen dickklumpiger Coagula, aber auch mitunter noch 25 Minuten nach dem Genusse das Erbrechen von Milch, in der keine Spur von Ausfällung wahrzunehmen ist.

\section{Die Ansnutzung der Kuhmilch im Verdauungstractus.}

Ich komme nun zu dem wichtigen Capitel der Ausnutzung der Kuhmileh bei der Verdaung und berichte zunächst wiederum iiber das Ergebniss künstlicher Digestion, um zu zeigen, wie verschieden die Menge des sich bildenden Peptons bei gleichen Mengen derselben Milch sein kann, wenn in der Behandlung, bzw. in dem Zusatze irgend welche Unterschiede bestehen.

1) $25 \mathrm{ccm}$ amphoter reagirender Kahmilch (Proteïngehalt 4,41\%) werden mit 20,0 künstlichen Magensafts von $2 \%$ Salzsäure 4 Stunden zur Digestion verstellt und nicht geschüttelt. Die Flocken vereinigen sich frühzeitig zu einem grossen Coagulum. Die Menge des gebildeten Peptons ${ }^{1}$ ) beträgt $=$

$$
0,762 \text { d. h. } 69 \% \text { des vorh. Proteïns. }
$$

2) Es werden $25 \mathrm{ccm}$ der nämlichen Milch mit 20,0 künstlichen Magensafts von $2 \%$ Salzsäure stark ges ch üttelt, dann 4 Stunden zur Digestion gestellt und während derselben alle 5 Minuten geschüttelt. Kein zusammengeballtes Coagulum. Die Menge des gebildeten Peptons beträgt $=$ 0,85 , d. h. $76 \%$ des vorhanden gewesenen Proteïns.

3) Es werden $25 \mathrm{ccm}$ der nämlichen Kuhmilch mit 33,5 künstlichen Magensaftes von $2 \%$ Salzsäure langsam und unter starkem Schütteln ge-

1) Es ist darunter die gesammte Proteïnmasse des Filtrates der verdauten Milch verstanden. Diese Proteïnmasse enthält allerdings noch geringe Mengen Albumin und Acidalbumin, die durch Kochen und Neutralisation zu entfernen sind. Da aber in dem Filtrate das nicht peptonisirte Proteïn nur etwa $2-5 \%$ des peptonisirten ausmachte, so habe ich der Einfachheit wegen das Quantum der Gesammtmasse als Pepton notirt. Geworınen wurde dieses, wie schon oben angegeben, durch Fällung des Filtrates mit Tannin, der Niederschlag bei $110^{\circ}$ getrocknet, schliesslich verascht. 
mischt und dann vier Stunden zur Digestion gestellt. Die Menge des gebildeten Peptons beträgt $=$

0,890, d. h. $81 \%$ des vorhanden gewesenen Proteïns.

4) Es werden $25 \mathrm{ccm}$ der nämlichen Kuhmilch mit 7,5 künstlichen Magensafts von $2 \%$ Salzsäure gemischt, geschüttelt, dann vier Stunden zur Digestion gestellt. Gerinnung sehr derbe. Die Menge des gebildeten Peptons beträgt $=$

0,549 , d. h. etwa $50 \%$ des vorhanden gewesenen Proteïns.

5) $25 \mathrm{ccm}$ der nämlichen Milch werden mit 39,5 künstlichen Magensafts von $1,5 \%$ Salzsäure und $0,5 \%$ Milchsäure versetzt, stark geschüttelt, 4 Stunden zur Digestion gestellt und während derselben alle 5 Minuten geschïttelt. Die Menge des gebildeten Peptons beträgt $=$

0,901, d. h. $82 \%$ des vorhandenen Proteïns.

Diese Ziffern lehren, dass die Menge des Peptons in Proportion steht zur Derbheit der initialen Gerinnsel. Wo diese am beträchtlichsten, wie in 4), ist auch jene Menge am geringsten; wo die Gerinnsel am lockersten, wie in 3), da ist die Peptonmenge am beträchtlichsten. Da nun die Derbheit und Grösse der Gerinnsel im Wesentlichen abhängig ist von der relativen Menge an verdinnter Säure, so ist auch das Quantum des gebildeten Peptons von eben demselben Factor, also auch von der relativen Menge des vorbandenen Verdauungsaftes abhängig.

Um die Ausnützung der Milch im gesammten Verdau ungstractus zu eruiren, habe ich Versuche an mir selbst und an Säuglingen ausgeführt. Zur Würdigung der an mir selbst constatirten Resultate will ieh vorauf bemerken, dass ich seit Jahren an reichlichen, täglichen Genuss von Milch gewöhnt, dieselbe sehr gut vertrage, insbesondere dureh sie keinen Magendruck, keine Leibschmerzen bekomme. Die Versuche wurden in der Weise angestellt, dass ich vor ihrem Beginn Fleisch und Grobbrot ass, dann nach 5 Stunden den ausschliesslichen Genuss von Milch begann, in mehrfachen Absätzen von jedesmal 13/4 Stunden im Ganzen 1500-1750 cem trank, volle 12 Stunden fastete, dann wieder Fleisch und Grobbrot ass and nunmehr die Fäces sammelte, deren helle Partieen dem Versuche mit der Milch entsprachen.

Die Säuglinge, deren Fäces untersucht wurden, waren selbstverständlich solche, bezüglich derer ich die Gewissheit hatte, dass sie ausschliesslich Kuhmilch erhielten. Sie standen im Alter von 
4 Wochen bis 12 Monaten und waren gesund. Die ihnen gereichte Milch stammte aus der hiesigen Molkereigenossensehaft, welche besondere Kindermilch feil hält. Bei der Aufsammlung der Fäces ist die grösste Sorgfalt beobachtet worden; Fernhaltung des Urins konnte jedoch nur bei den älteren Säuglingen erzielt werden.

Die Methode der Untersuchung war folgende 1): Es wurde die Menge, der Wassergehalt, ferner der etwaige Gehalt an Eiweissstoffen, an Fetten, an Zucker, an Salzen festgestellt und das Resultat der quantitativen Analyse mit dem Gehalte der ingerirten Knhmilch verglichen.

Die Bestimmung des Wassergehaltes geschah dureh Trocknung der frischen Fäces bei $110^{\circ} \mathrm{C}$. bis zur Gewichtsconstanz.

Zur Bestimmung der Eiweissst offe benutzte ich folgende Methode: die frischen oder nach Umständen die getrockneten und dann gepulverten Fäces wurden, nachdem sie gewogen, mit stark verdünnter Salzsäurelösung (4-5: 1000) behandelt, das Filtrat mit Tannin versetzt, der Niederschlag auf gewogenem Filter gesammelt, bei $110^{\circ} \mathrm{C}$ getröcknet, gewogen, verascht und wieder gewogen.

Die Bestimmung der Fette, der freien und gebundenen Fettsäuren habe ich auf folgende Weise vorgenommen:

Die getrockneten und gepulverten Fäces wurden gewogen, dann mit salzsäurehaltigem Aether erschöpfend extrahirt. Das Extract, welches ja auch die Fettsäuren enthält, die an Alkali oder Kalk, resp. Magnesia gebunden waren, wurde verflüchtigt, der Riickstand getrocknet, gewogen.

Die Prüfung auf Zucker geschah in nachfolgender Weise: frische Fäces behandelte ich mit Alcohol, verdunstete das alcoh. Extract, löste den Rückstand in destillirtem Wasser und kochte dann mit Fehling'scher Lösung.

Zur Untersuchung des Salzgehaltes empfiehlt es sich, nicht die getrocknete und gepulverte Masse der Fäces einfach zu veraschen, sondern die Rückstände des alcoh. und wässrigen Extractes, sowie den schliesslichen Rückstand der extrahirten Substanz jeden für sich zu veraschen und die Gewichtsziffern zu addiren. Nach dieser Methode habe ich verfahren. Sie ist ja recht

1) Ueber die Methode vergleiche man die Abhandlung des Verfassers im D. Archiv für klinische Medicin XXVIII, S. 437.

E. Pflüger, Archiv f. Physiologie. Bd. XXIX. 
umständlich, liefert aber ein sehr genaues und zweifellos ein viel genaueres Resultat, als wenn man die getrockneten Fäces einfach verascht.

Die Fäces bei aussebliesslichem Genusse von Kuhmilch sind, wenn diese gut verdaut wird, gelbweiss, ziemlich consistent, schwach sauer riechend, schwach sauer reagirend. In ihnen findet die chemische Untersuchung von den Bestandtheilen der Milch wieder $=$ Eiweiss, Fett und Salze. Der Zucker ist verschwunden; wahrscheinlich darf aber die in den Fäces fast immer nachweisbare Milchsäure zu einem Theil als aus ihm hervorgegangen betrachtet werden.

Das Eiweiss, meist nur in geringfügiger Menge, ist als Albumin, resp. Casein, und als Acidalbumin vorhanden; mitunter zeigt sich auch etwas Pepton. Das Fett findet man als Neutralfett, als Fettsäure und als fettsaures Alkali resp. Erdsalz. Von den Salzen der Milch sind alle, besonders jedoch Kalksalze, zu constatiren.

1) Versuche an mir selbst.

a. Consum $1500 \mathrm{ccm}$ einer Milch, die enthielt:

$=4,43 \%$ Eiweissstoffe, 3,90\% Fett, 3,77\% Zucker, 0,58\% Salze, also $=12,68 \%$ Trockensubstanz, in Summa 190,0 Trockensubstanz.

Menge der gelbweissen Fäces = 74,0, d. h. 4,9\% der genossenen Milch.

Trockenrückstand von 74,0 Fäces $=18,9$, d. h. 25,5\% derselben und fast $10 \%$ der Trockensubstanz der Miloh.

Wassergehalt der Fäces . . . . $=74,5 \%$.

Eiweisssubstanz fand sich . . . . = 0,89, d. h. 4,7\% der Trockensubstanz der Fäces.

Fett, freie und gebundene Fettsäuren $=3,91$, d. h. $21,2 \%$ der Trockensubstanz der Fäces.

Salze . . . . . . . . . . . $=4,86$, d. h. $26 \%$ der Trockensubstanz der Fäces.

Zucker . . . . . . . . $=0$.

Es waren also ausgenntzt

$$
\begin{aligned}
& \text { das Eiweiss zu . . . . . . . }=98,7 \% \text {. } \\
& \text { das Fett zu . . . . . . . . }=93,4 \text {, } \\
& \text { die Salze zu . . . . . . . . }=44,2 \text {, } \\
& \text { der Zucker zu . . . . . . . }=100 \text { " } \\
& \text { die gesammte Trockensubstanz zu }=90 \text { " }
\end{aligned}
$$

b. Consum $1750 \mathrm{ccm}$ Milch, die enthielt:

$12,8 \%$ Trockensubstanz, nämlich

$4,15 \%$ Eiweiss, 4,08 \% Fett, 3,96\% Zucker, 0,61\% Salze. 
Menge der gelbweissen Fäces $=77,5$, d. h. 4,3\% der genossenen Milch.

Trockenrückstand von $77,5=18,06$, d. h. 24,9\% der Fäces und 8,4\% der Trockensubstanz der Milch.

Eiweisssubstanz fand sich . . . . = = 0,69, d. h. 3,8\% der Trockensubstanz der Fäces.

Fett, freie und gebundene Fettsüuren $=3,15$, d. h. $17 \%$ der Trockensubstanz der Fäces.

Salze . . . . . . . . . . . $=4,61$, d. h. $25,5 \%$ der Trockensubstanz der Fäces.

Zucker . . . . . . . . . . $=0$.

Es waren also ausgenutzt

$$
\begin{aligned}
& \text { das Eiweiss der Milch zu. . . . }=98,4 \% \\
& \text { das Fett zu . . . . . . . . }=95,6 \% \\
& \text { die Salze zu . . . . . . . . }=56,6 \% \\
& \text { der Zucker zu . . . . . . . }=100 \% \\
& \text { die gesammte Trockensubstanz zu }=91,6 \%
\end{aligned}
$$

c. Consum $1600 \mathrm{ccm}$ Milch von dem nämlichen Gehalt wie die vorige. Menge der gelbweissen Fäces . . . . $=66,0$.

Trockenrückstand . . . . . . . . $=17,1$, d. h. $26,2 \%$ der Fäces.

Wassergehalt der Fäces . . . . . $=73,8 \%$.

Eiweisssubstanz . . . . . . . $=0,140$, d. h. $0,8 \%$ der Trockensubstanz.

Fett, freie und gebundene Fettsäuren . = 3,951, d. h. $23,1 \%$ der Trockensulstanz.

Salze . . . . . . . . . . . . $=4,284$, d. h. $25 \%$ d. Trockensubstanz.

Zucker . . . . . . . . . . . . $=0$.

Es waren demnach ausgenutzt

$$
\begin{aligned}
& \text { die Eiweisssubstanz zu . . . . . 99,2\%. } \\
& \text { das Fett zu . . . . . . . . . 93,5 " } \\
& \text { die Salze zn . . . . . . . . } 56,2 \text { " } \\
& \text { der Zucker zu . . . . . . . . } 100 \text { " } \\
& \text { die Trockensubstanz zu . . . . . 91,7 " }
\end{aligned}
$$

2) A. S. 5\% Monate alter Knabe, gut genährt, erhält die Kindermilch der hiesigen Molkereigenossenschaft im Verhältniss von 2 Theilen zu 1 Theil Wasser. Sein Totalconsum ist in der Untersuchungswoche an Milch = $9400 \mathrm{ccm}$.

Die gesammten Fäces dieser Woche wogen frisch $=272,00 \mathrm{gr}$

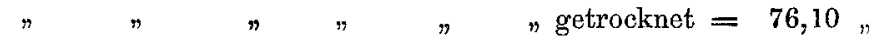

Eiweiss fand ich in den $76,1 \mathrm{gr}$ getrockneter Fäces $=2,80$ "

Fett, freie und gebundene Fettsäuren . . . . . = 18,91 "

Salze . . . . . . . . . . . . . . . . . $=28,84$,

Zucker . . . . . . . . . . . . . . . . $=0$ " 
$\mathrm{Da}$ die Milch enthielt

4,8\% Proteï, 4,00\% Fett, 3,79\% Zucker und 0,62\% Salze, so waren ausgenutzt:

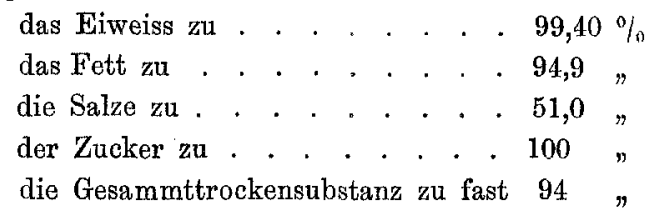

3. Leo M., geboren am 16. October 1879, wurde in den ersten elf Lebenswochen mit Kuhmilch ernährt, welcher allmählich verringerte Mengen Wasser zugesetzt wurden. Nachher folgte eine Ernährung mittelst Kuhmilch und Gerstenschleim.

Die Untersuchung erstreckte sich auf vier Tage der vorletzten Woche des November 1879. In diesen vier Tagen nahm das völlig gesunde Kind zu sich an Milch durchschnittlich pro Tag $=600 \mathrm{ccm}$, im Ganzen demnach $=2400 \mathrm{ccm}$. Diese Milch hatte einen Trockenrückstand von 12,60\% und enthielt

$$
\begin{array}{ll}
\text { Proteïnstoffe } & =4,44 \%, \\
\text { Fett } & =3,65 \%, \\
\text { Zucker } & =3,96 \%, \\
\text { Salze } & =0,55 \% .
\end{array}
$$

Die gesammten Fäces betrugen frisch $=73,5 \mathrm{gr}^{1}$ ).

$$
" \quad " \quad \text { " getrocknet }=19,2 \text { " }
$$

In ihnen fand ich:

$$
\begin{aligned}
& \text { Fiweiss }=2,01 \mathrm{gr}, \\
& \text { Fett etc. }=4,86 " \\
& \text { Salze }=6,18 " \\
& \text { Zucker }=-"
\end{aligned}
$$

Es waren demnach ausgenutzt worden

$$
\begin{aligned}
& \text { das Eiweiss zu . . . . . . }=98,2 \%, \\
& \text { das Fett zu . . . . . . . }=94,8 \%, \\
& \text { die Salze zu . . . . . . . . }=53,3 \%, \\
& \text { der Zucker zu . . . . . . . }=100 \%, \\
& \text { die Gesammttrockensubstanz zu }=93,7 \% .
\end{aligned}
$$

4. H. P., vier Wochen alter Knabe, gut entwickelt, wird mit Kuhmilch ernährt, welche im Verbältniss von $1 \mathrm{Th}$. zu $1 \mathrm{Th}$. Wasser gemischt isi. Diese Milch ist aus der nämlichen Quelle wie die, welche der sub. 3 notirte Knabe bekommt. Doch wurde ihre Zusammensetzung noch einmal bestimmt. Sie war jetzt folgende:

1) Die Menge war etwas grösser, weil beim Sammeln nicht wohl die ganze Masse gewonnen werden konnte. 


$$
\begin{aligned}
& 4,47 \% \text { Proteïn, } \\
& 4,00 \% \text { Fett, } \\
& 3,62 \% \text { Zucker, } \\
& 0,57 \% \text { Salze. }
\end{aligned}
$$

Der Tagesconsum betrug im Durchschnitt 650,0 ccm Nahrung mit einem Gehalte von $325 \mathrm{ccm}$ Milch, in zwei Versuchstagen also $650 \mathrm{ccm}$ Milch.

Es wurden nun die Fäces beide Tage hindurch gesammelt, was gut gelang, da dieselben sehr consistent waren:

Menge der Fäces an beiden Tagen $=52,00$,

Trockensubstanz derselben . . . = 8,320,

Eiweisssubstanz in letzterer . . . = 0,241, d. h. $2,9 \%$,

Fett, freie und gebundene Fettsäuren $=2,05$, d. h. 24,7"

Salze . . . . . . . . . . . $=2,02 \%$

Zucker . . . . . . . . . . $=0$

Es waren also ausgenutzt

das Eiweiss zu . . . . . . $=99,2 \%$,

das Fett zu fast. . . . . . $=92,2$,

die Salze zu . . . . . . . $=45,4$ "

der Zucker zu . . . . . . $=100$ "

die Gesammttrockensubstanz zu $=90$ "

5. J. S., ein sehr gut entwickelter Knabe von 11/4 Monaten. Die Ernährung erfolgt noch ausschliesslich mittelst Kuhmilch, die unverdünnt und ohne jeglichen Zusatz zu 2000,0-2150,0 ccm pro Tag genossen wird, Quelle und Zusammensetzung derselben wie die sub 4 erwähnte. Zwei Versuchstage.

Menge der Fäces an beiden Tagen $=126,00$,
Trockensubstanz . . . . . . . $=20,40$,
Eiweiss in letzterer . . . . . . $=1,38$,
Fett, freie und gebundene Fettsäuren $=5,52$,
Salze . . . . . . . . . . . . $=5,17$,
Zucker . . . . . . . . . . $=0$

Es waren also ausgenutzt

das Eiweiss zu . . . . . . = $=98,5 \%$,

das Fett $\mathrm{zu}$. . . . . . . $=93,3^{\prime \prime}$

die Salze zu . . . . . . . $=57$,

der Zucker zu . . . . . . $=100$ "

die Gesammttrockensubstanz zu $=92,3$ "

Die vier Säuglinge verdauten demnach die Kuhmilch:
1) $\mathrm{zu} 94,0 \%$
2) zu 93,7,
3) zu 90,0 ,
4) $\mathrm{zu} 92,3$

im Durchschnitt zu $92,50 \%$, während bei mir selbst die mittlere Ausnutzung war $=90,5 \%$. 
Vergleichen wir diese Resultate mit den Ergebnissen, welehe Andere bei ihren Untersuchangen erhielten, so können wir eine ziemlich genaue Uebereinstimmung constatiren. Gerber ${ }^{1}$ ) fand eine allgemeine Ausnutzung der Trockensubstanz der Kuhmileh zu $92,2 \%$, Rubner $^{1}$ ) eine solche von $89,8 \%-92,3 \%$, beide bei Erwachsenen, und Forster ${ }^{2}$ ) bei einem Säuglinge eine solche von $93,65 \%$. Auch diese Data zeigen also, dass das Kind die Kuhmilch besser verdaut, als der Erwachsene.

Nächst dem $Z$ u cker scheint stets das Eiweiss am besten ausgenutzt $\mathrm{zu}$ werden. Ich fand es meistens in nur geringer Menge; das Maximum betrug bei Säuglingen ca. $3 \%$, bei mir selbst 4,7\% der Trockensubstanz des Fäces. Die Ansicht, dass es in den letzteren nach dem Genuss ron Kuhmilch ganz fehle, darf hiernach jedenfalls nicht aufrecht erhalten werden. Es kann fehlen, aber dies ist keineswegs Regel, wahrscheinlich sogar Ausnahme. Dass es unter Umständen in grösserer Menge vorkommen kann, habe ich noch kürzlich constatiren können. Es enthielten nämlich die gehackt aussehenden Fäces eines 6-wöchentlichen, mit Kuhmilch und Wasser zu gleichen Theilen ernährten Knaben gegen $6,5 \%$ der Trockensubstanz Eiweiss. Aber man darf wohl annehmen, dass, wenn dieses zu mehr als $3 \%$ sich bei Säuglingen findet, eine normale Verdauung nicht mehr Statt hat.

Rubner hat bei seinen Feststellungen einen recht erheblichen Stickstoffgehalt der Fäces nach Kuhmilchgenuss constatirt and die Ausnutzung des $\mathrm{N}$ zu $88-93 \%$ berechnet. Dies scheint mit den Ergebnissen meiner Untersuchungen nicht zu harmoniren. Aber man muss eben in's Auge fassen, dass Jener nicht den Eiweiss-, sondern den Stickstoffgehalt der Kuhmileh und der Fäces mit einander vergleicht. Ich selbst habe zu wiederholten Malen ${ }^{3}$ ) darauf aufmerksam gemacht, dass man aus dem geringen Eiweissgehalt der Darmentleerungen noch nicht auf eine dementsprechend gute Ausnutzung des Eiweisses schliessen dürfe und diese letztere unter allen Umständen weniger hoch berechnen müsse, weil in den Fäces sehr viel Mycoproteïn - Proteïn der massenhaften Bacterien und Coccen - sich fände, das bei der gewöhnlichen Ana-

1) Rubner: in Zeitschrift für Biologie 1880. 16.

2) Forster: Aerztl. Intelligenzblatt f. Baiern. 1878. Märzheft.

3) Uffelmann, Deutsches Archiv für kl. Medicin XXVIII, Seite 472 und Handbuch der Hygiene des Kindes S. 228. 
lyse nicht mit gewonnen werde. Ausserdem enthalten ja die Fäces noch Stickstoffkörper, die, während des Verdaunngsprocesses ans dem Eiweiss der Nahrung entstanden, bei der Untersuchung auf Eiweisssubstanz unberücksichtigt bleiben. Die Nichtübereinstimmung der Rubner'schen Zahlen und meiner eigenen ist deshalb nur eine scheinbare.

Weniger gut, als die Ausnutzung des Eiweisses war diejenige des Fettes. Dieselbe schwankte bei Säuglingen von $93 \%-94,9 \%$, bei mir von $93,4 \%-95,6 \%$, so dass sie also bei jenen, umgekehrt wie die des Eiweisses, weniger gut war. Rubner fand, dass das Fett zu 92,9\%--95,4\% verdaut wurde. Unsere Uebereinstimmung ist hier demnach eine nahezu vollständige.

Die Berechnung des Fettgehaltes enthält genau genommen iibrigens gleichfalls einen, allerdings nicht bedeutenden, Fehler. In dem Aetherextracte der Fäces finden sich nämlich auch solche Substanzen, die nicht oder nicht nothwendig vom Fett der Nahrung abstammen, z. B. Cholestearin. Die Menge desselben beträgt jedoch im Mittel nur 0,8\% der Trockensubstanz, wenigstens bei Sänglingen. Deshalb muss der Procentsatz der Fettausnutzung eigentlich ein wenig höher berechnet werden, als soeben geschehen ist.

Sehr wenig gut stellt sich die Verdauung der Salze. Ungefähr die Hälfte der Gesammtmasse derselben geht unausgenutzt mit den Fäces ab. Bei mir selbst constatirte ich eine Verdauung von $44,2-56,6 \%$, bei Säuglingen von $45,4 \%-57 \%$. Die Schwankungen waren also recht bedeutend. Rubner fand eine Ausnutzung von 51,8\% - 55,5\% beim Erwachsenen.

Ungemein gering ist diejenige der Kalksalze. Man darf rechnen, dass nur etwa 25\%--30\% der eingeführten Menge zur Aufsaugung gelangen, während gegen $75 \%-78 \%$ des Kalkes der Muttermilch verdaut wird ${ }^{1}$ ). Dies rührt zum Theil daher, dass die absolute Menge des in der Kuhmilch enthaltenen Kalkes grösser ist, als in der Muttermilch, das Kind aber nur soviel aufnimmt, als es bedarf. Von Belang dürfte ausserdem sein, dass die derbflockige Gerinnung der Kuhmileh die Ausnutzung auch des Kalkes erschwert; ein Umstand, welcher bei subnormalem Gehalte der

1) Forster, Aerztl. Intelligenzblatt für Baiern 1878. Märzheft und Uffelmann, D. Archiv f. kl. Medicin XXVIII, S. 472. 
Milch an Kalk für Säuglinge selbstverständlich sehr folgenschwer sein kann.

\section{Gekochte Milch.}

Beim Kochen wird die Milch in mehrfacher Hinsicht verändert. Zunächst findet eine Verdrängung der in ihr befindlichen Gase Statt. Es sind dies Kohlensäure, Sauerstof f und Stickst off. Die Gesammtmenge derselben scheint sehr schwankend zu zu sein. Setschenow fand

$\begin{array}{ccl}5,65-6,72 & \text { Volumprocente } & \text { Kohlensäure, } \\ 0,16-0,32 & , & \text { Sauerstoff, } \\ 1,34-1,64 & " & \text { Stickstoff. }\end{array}$

Pfl ïger ${ }^{2}$ ) constatirte in 100 Volumina Kuhmilch

$$
\begin{array}{rll}
=7,60 & & \text { Kohlensäure, } \\
0,09 \text { u. } 0,10 & " & \text { Sauerstoff, } \\
0,70 & " & \text { Stickstoff. }
\end{array}
$$

Beim Kochen werden auch gewisse Riechstoffe der Milch verfluichtigt. Denn während des Siedens lässt sich regelmässig ein eigenthümlicher, schwer zu definirender Geruch wahrnehmen, und ausserdem besitzt die in gewöhnlicher Weise gekochte Milch nicht mehr den angenehm nussartigen Geruch der frischen.

Die Verflichtigung von Wasser ist versehieden stark je nach der Dauer des Kochens and der Beschaffenheit des Kochgefässes. Beim einmaligen raschen Aufsieden in einem Gefässe mit weiter Oeffnung pflegt die Milch etwa $5 \%$ ibres Gewichts zu verlieren, beim einmaligen Aufsieden in einem enghalsigen Gefässe dagegen nur $0,46 \%-0,52 \%$, bei viermaligem rasch auf einander folgenden Aufsieden in ebensolchem Gefässe nur 2,2\%.

Die Reaction der Kuhmilch wird, wenn sie vorher eine amphotere war, durch das Kochen in Folge der Verjagung von Kohlensäureeine alkalisehe. Säuerliche Milch bleibt säuerlich, alkalische bleibt alkalisch.

Beim Sieden der Milch in offenen Gefässen mit nicht enger Oeffnung und bei unbehindeter Verdunstung entsteht die sog. Kochbaut. Entfernt man sie und setzt man das Sieden fort, so bildet sie sich auf's Nene. Die ersten Spuren der Haut zeigen

1) Setschenow, Zeitschrift für rationelle Medicin 3. Reihe X. S. 285.

2) Pflüger, Archiv für Physiologie, 1869, S. 166. 
sich, wenn die Milch eine Temperatur von $60^{\circ} \mathrm{R} .=75^{\circ} \mathrm{C}$. angenommen hat. Gar keine Kochhaut entsteht, wenn das Sieden in einem Gefässe mit engem Halse vorgenommen, die Verdunstung inhibirt wird, and wenn die Milch, die man kocht, einen bestimmten Grad von Säure hat. In letzterem Falle gerinnt sie beim Sieden. Untersucht man die Haut genauer, so stellt sich folgendes heraus: Sie hat weissliches, bläulich weisses oder gelblich weisses Aussehen und weiche, beim Erkalten zäher werdende Consistenz. Breiten wir ein kleines Partikelchen unter dem Microscope aus, so erblicken wir Nichts als Fetttröpfchen, und zwar sehen wir kleine, mittelgrosse und grosse, die letzteren meistens noch rundlich, wie in der rohen Milch, andere aber auch länglichrund, sowie unregelmässig contourirt. Spült man die Kochhaut zuvor in destillirtem Wasser reichlich und wiederholt $a b$, so sieht man mittelst des Microscops auch jetzt fast Nichts als Fetttröpfehen. Es ist also klar, dass letztere der Haut nicht ankleben, sondern dass sie ein Constituens derselben sind. An einzelnen Stellen aber, an welchen sie weniger dicht aneinandergedrängt liegen und am Rande des Präparates erkennt man, dass auch eine structurlose, hyaline Masse vorhanden ist, welche jene Tröpfehen in sich aufnimmt und festhält. Anderweitige Formelemente, speciell Krystalle irgend welcher Art, enthält die Kochhaut nicht.

Die chemische Untersuchung lehrt, dass sie im Wesentlichen alle Bestandtheile der Milch in sich führt.

Zusatz von verdünnter Kalilauge macht sie sofort erblassen und erweicht sie so, dass sie zerfällt. Behandelt man die dann entstehende trübe Flïssigkeit mit Aether so lange, bis eine Probe eines neuen Zusatzes desselben beim Verdunsten keinen Fleck mehr hinterlässt, und filtrirt man dann die zurückbleibende, von Fett befreite Flüssigkeit, so erhält man ein ganz klares Filtrat. Dieses gibt

1) mit verdünnter Milchsäure, verdünnter Essigsäure einen starken Niederschlag, der bei Zusatz von concentrirter Essigsäure sich wieder löst,

2) mit Phosphorwolframsäure einen starken Niederschlag,

3) mit alc. Kupfervitriollösung eine violette Farbe.

Filtrirt man den auf Zusatz verdünnter Essigsäure erhaltenen Niederschlag ab, so gibt das Filtrat beim Kochen nicht ganz unbeträchtliche Trübung. 
Nach diesen Reactionen enthält die Kochbaut Albuminate; dieselben bilden augenscheinlich die Grundmasse, in welcher die Fettröpfchen eingebettet sind. Was die Natur der Albuminate betrifft, so ist klar, dass ein sebr erheblicher Procentsatz derselben als Casein sich vorfindet, da das Filtrat mit verdünnter Essigsäure oder Milchsäure starke Ausfällung zeigt. Ein Theil ist aber auch als Albumin vorhanden, da die vom essigsauren Niederschlage befreite Flitssigkeit beim Kochen sich tribt.

Kocht man das mit Kalilauge und Kupfervitriol versetzte Filtrat, welches in der Kälte violette Farbe zeigte, einige Minuten hindurch, so verändert sich die Farbe in eine fahle oder schwach gelbliche, nicht in eine braun-röthliche. Wohl aber zeigt sich letztere, wenn man die Kochhaut nicht vorher in destillirtem Wasser abspült, sondern ohne Weiteres mit verdünnter Kalilange behandelt, das Fett durch Aether entfernt und dann Kupfervitriol zusetzend kocht. Es ist darnach in ihr urspruinglich Zucker vorhanden.

Verascht man eine Kochhant, so erhält man eine grauweisse Masse, die mit Salzsäure schwach aufbraust. Die salzsaure Lösung gibt mit Aetzammoniak einen weissen, flockigen Niederschlag. Essigsäure erzengt beim Erwärmen eine kaum erkennbare Gelbfärbung, oxalsaures Ammoniak aber gibt einen stark weissgrauen Niederschlag in der mit Aetzammoniak versetzten Flüssigkeit. Filtrirt man diesen weissgrauen Niederschlag ab, so erzengt Ammoniak in dem klaren Filtrate einen ungemein schwachen, das Vorhandensein kleinster Mengen von Magnesia andentenden Niederschlag.

In einfach wässriger Lösung der Asche gibt Argentum nitricum schwache, in Salpetersäure unlösliche Ausfällung. Wird die wässrige Lösung nahezu verdunstet und dann auf dem Platindraht in eine Spiritusflamme gebracht, so tritt eine eben noch erkennbare Gelbfürbung auf. Platinchlorid gibt nach Zusatz von etwas Alcohol und Salzsäure eine schwach gelbliche Trübung, Chlorbarium nach vorgängiger Ansäuerung mittelst Salzsäure einen in letzterer und in Wasser unlöslichen Niederschlag. Fügt man der wässrigen Lösung der Asche zuerst Chlorammonium und Aetzammoniak, dann eine Lösung von schwefelsaurer Magnesia hinzu, so zeigt sich eine schwache, weissliche Trübung.

Um diese Reactionen zu erbalten, bedarf es nicht sehr be- 
trächtlicher Mengen Asche; diejenige auf Kalk constatirt man sogar schon bei einem Quantum von nur wenigen Milligrammes.

Die Kochhant hat also Kali, Natron, Magnesia, Eisen, Kalk und Kohlensäure, Schwefelsäure, Phosphorsäure, Chlor.

Quantitativ prävalirt der Kalk ganz ausserordentlich; er bildet die Asche zu $40-43 \%$, während er in derjenigen der Milch zu nur $28-30 \%$ anwesend ist.

Noch mehr interessirt es, zu wissen, wie viel von den eigentlichen Nährstoffen aus der Milch in die Kochhant iibergeht. Um dies zu zeigen, lasse ich das Resultat zweier Analysen folgen, die ich angestellt habe.

I. Kochhant $\left.^{1}\right)=3,829$, getrocknet $=1,506$

Aetherextract . . . . . . . $=0,617$

Eiweisssubstanzen . . . . $=0,820$

Zucker . . . . . . . . . $=0,062$

Salze . . . . . . . . . . $=0,007$

II. Kochhaut $=2,908$, getrocknet $=1,086$

Aetherextract . . . . . . . $=0,283$

Eiweisssubstanzen . . . . $=0,751$

Zucker . . . . . . . . $=0,046$

Salze . . . . . . . . . $=0,006$.

In diesen beiden Analysen zeigt besonders der Gehalt an Fett, doch auch der an Eiweiss einen erbeblichen Unterschied. Derselbe ist zweifellos durch die Verschiedenheit der verwendeten Milch bedingt gewesen; die ad 1) verwendete war sehr fettreich, die ad 2) verwendete dagegen fettarm.

Im Allgemeinen darf man annehmen, dass die Kochhaut zu etwa $60-62 \%$ aus Wasser, zu $38-40 \%$ aus Nährstoffen besteht, und dass mindestens $21 \%$ der Haut $=$ Eiweiss, dass $10-16 \%$ derselben $=$ Fett ist.

Wenn nun beim einmaligen Aufkochen von 1000,0 cem Kuhmilch $=9,0$ bis 10,0 Kochhaut sich bilden, so gehen von den in $1000,0 \mathrm{ccm}$ Milch enthaltenen 44,0-45,0 Eiweiss ca. 2,0, von den in demselben Quantum enthaltenen 40,0 Fett ca. 1,0-1,6 in die Kochhaut über und eventuell verloren. Nach Wegnahme der letzteren bleibt eine Milch zurück, die, wenn das Aufsieden rasch geschah, ca. 940,0 cem, wenn es länger dauerte nur noch ca.

1) Nebst der anhaftenden, nicht mehr abträufelnden Flüssigkeit. 
900,0 cem cem ausmacht, und in ersterem Falle unter obiger Voraussetzung $\left.{ }^{1}\right)=4,59 \%$, in letzterem Falle $=4,66 \%$ Eiweiss enthält.

Dies Resultat wird selbstverständlich anders ausfallen, wenn man länger siedet, weil dadurch eine dickere Haut und stärkere Verdunstung von Wasser erzielt wird.

Nach dem Vorstehenden darf man die Ansicht also fernerhin nicht mehr aufrecht erhalten, dass die Kochhaut nur aus Caseïn bestehe. Eine solche Ansicht findet sich ziemlich allgemein vertreten; u. A. liest man sie noch bei König: die menschlichen Nahrungs- und Genussmittel II. Seite 183 und bei Bie dert: Ueber Kinderernährung Seite 90 . Die Kochhaut enthält vielmehr in jedem Falle die sämmtlichen Bestandtheile der Milch, nur in einem anderen Verhältnisse, als die letztere.

Man kann übrigens die Bildung der Kochhaut verhüten und zugleich der Milch einen Antheil an den ihr eigenthümlichen Riechstoffen wahren, wenn man die Verdunstung beim Sieden fernhält. Dies geschieht am einfachsten, wenn man es in einem Behälter mit langem, engem Halse vornimmt, z. B. in einer Kochflasche oder einem ihr nachgebildeten Apparate aus Weissblech. In dem Augenblicke, in welchem der Siedepunkt erreicht wird, entsteht dann ein Schaum, der in den Hals aufsteigt; aber von einer Haut ist selbst bei längerem Kochen Nichts zu sehen. Da bei dieser Methode der Wasserverlust sehr gering ist, so wird bei ihrer Anwendung am allerbesten die natïrliche Beschaffenheit der Kuhmileb enthalten.

In neuerer Zeit hat man angefangen, für gewisse Zwecke die Milch unter erhöhtem Drucke zu kochen. Dies kann sehr einfach im Papinianischen Topfe geschehen, indem man in ihn etwas Wasser giesst und nunmehr den Behälter mit Milch hineinstellt. Bertling gab einen besonderen Apparat an, in welchem nach der Angabe des Erfinders die Milch unter erhöhtem Druck und bei erhöhter Temperatur ohne Gefahr des Anbrennens und Ueberkochens gekocht werden kann. (Ein luftdichter Verschluss findet jedoch thatsächlich nicht Statt.) Die im Handel erscheinende flüssige conservirte Milch, z. B. die Scherff's, wird thatsächlich unter erhöhtem Druck (4-5 Atmosphären) gekocht. Man füllt

1) Dass sie nämlich vor dem Kochen $=4,5 \%$ Eiweiss enthielt. 
zu dem Zwecke starke Glasflaschen mit Milch, verkorkt dieselben fest und setzt sie nun unter Dampfdruck während 1--2 Stunden einer Hitze von $100^{\circ}-120^{\circ} \mathrm{C}$. aus. Wenn man zu Zwecken der Untersuchang nur kleinerer Mengen unter Hochdruck gekochter Milch bedarf, so kann man sich sehr zweckmässig dicker Glasröhren bedienen, die mit Milch gefüllt, an beiden Enden zugeschmolzen der Hitze ausgesetzt werden.

Die unter den hier beregten Verhältnissen gewonnenen Präparate zeigen zunächst eine gelbliche oder fahlgelbe Farbe statt der weissen einer gewöhnlich gekochten Milch. Dies rührt sicherlich her von einer Modification des Zuckers, da, wie wir sehen werden, Eiweissstoffe und Fett in erkennbarer Weise nicht modificirt werden. Ferner bekommt die auf erheblich mehr als anf $100^{\circ} \mathrm{C}$. erhitzte Milch, jedenfalls die in zugeschmolzener Glasröhre auf $120^{\circ} \mathrm{C}$. erhitzte, einen eigenthümlichen, ein wenig an Hefe erinnernden Geruch und einen nicht minder eigenthümlichen, schwach zusammenziehenden Geschmack. Im Uebrigen ist sie so fliüssig, dass sie aus einer Oeffnung ausfliesst, welche nicht mehr Umfang hat, als ein Nadelknopf. Microscopisch giebt sie genau das Bild der rohen Milch, verhält sich bei der Filtration genan wie diese und giebt nur ein klein wenig mehr Fett an Aether ab.

\section{Verdaulichkeit der gekochten Milch.}

Eine ungemein wichtige Frage, besonders der Hygiene des Säuglingsalters ist die, ob gekochte Milch hinsichtlich ihrer Verdaulichkeit der rohen gleichkommt, oder nachsteht oder sie ubertrifft. Man hörte und las dariber bislang die widersprechendsten Angaben; neuerdings trifft man aber bei medicinischen Schriftstellern immer häufiger die Behauptung, dass anhaltend, bezw. unter erhöhtem Druck gekochte Kuhmilch erheblich leichter als rohe verdaulich sei, dass sie in ihrem Verhalten dem Magensafte gegenüber sich der Frauenmilch nähere, die nur in zarten Flöekchen gerinne, nicht in derben Klümpchen. Eine solche Behauptung findet sich z. B. bei $A\left(b u^{1}\right)$, ferner bei $S_{0} \operatorname{tmann}{ }^{2}$ ), bei $\mathrm{Munk}^{3}$ ). Ist

1) Albu, Beschaffenheit guter Kuhmilch. 1880.

2) Soltmann, Breslauer ärztliche Zeitschrift 1881. 12. November.

3) Munk, D. medicinische Wochenschrift 1881, S. 36. 
sie wahr, so haben wir einen Grund mehr, die Milch den mit ihr ernährten Säuglingen niemals anders als anhaltend und unter erböhtem Druck gekocht darzureichen. Ich bin aber nicht in der Lage, den Autoren, welche dies behaupten, beizustimmen. Zahlreiche Versuche habe ich angestellt, aber alle lehrten mich, dass gekochte Milch hinsichtlich der Verdaulichkeit keinen Vorzug vor der ungekochten hat.

Das Resultat künstlicher Verdaungsversuche war, dass die gekochte Milch keine dünnflockigeren Gerinnsel bildete und nicht rascher oder vollständiger peptonisirte. Dies fand ich bei der gewöhnlich gekochten, bei der in einem Gefässe mit langem, engem Halse gekochten, bei der eine volle Stunde auf $120^{\circ} \mathrm{C}$, erhitzten Milch.

$10 \mathrm{ccm}$ rohe Kuhmilch gaben mit 16,0 einer Verdaungsflüssigkeit von $2 \%$ Salzsäure nach 4 St.

$$
=0,374 \text { Pepton und Neutralisationspräcipitat. }
$$

$10 \mathrm{ccm}$ gewöhnlich gekochter Kuhmileh der nämlichen Zasammensetzung gaben unter gleichen Verbältnissen:
1) $=0,363$ Pepton + Neutralisationspräcipitat
2) $=0,396 \quad "$
3) $=0,366 \quad$, $" \quad$ "
4) $=0,358$
:, $"$

Es ist dabei zu bedenken, dass 10,0 anf gewöhnliche Weise gekochte Milch etwas wasserärmer sind, als das gleiche Quantum roher Milch, dass aber der Gehalt an Eiweissstoffen in 10,0 der einen, wie in 10,0 der anderen nahzu gleich ist, wie dies aus der friheren Darstellung erhellt.

Es ergaben ferner:

10,0 einer ohne Bildung von Kochhant gekochten Milch derselben Quelle unter den beregten Verhältnissen

1) $=0,389$ Pepton und Neutralisationspräcipität.

2) $=0,367$

3) $=0,393$

$\begin{array}{ll}" & " \\ " & "\end{array}$

4) $=0,370$,

Ferner erhielt ich aus

10,0 einer Milch derselben Quelle, die eine Stunde auf $120^{\circ} \mathrm{C}$. (in einer zugeschmolzenen Glasröbre) erhitzt war ${ }^{1}$ ) unter den beregten Verbältnissen:

0,369 Pepton und Neutralisationspräeipitat.

1) Dies geschah durch Herrn Prof. Dr. Jasobsen in dessen chem. Laboratorium hierselbst. 
In diesem letzteren Falle waren die initialen Gerinnungen mindestens ebenso beträchtlich und ebenso derb, wie bei roher Milch, die zur Verdaunng gebracht wird. Gegen das Ende der zweiten Stunde fand sich an der Oberfläche der Flüssigkeit eine Fettschicht und inmitten der Flüssigkeit ein einziges CoaguIum von dem Umfange und der Dicke eines Fünfpfennigstïckes. Die Flïssigkeit selbst aber war molkenartig, nur wenig trübe und gab ein völlig klares Filtrat.

Aus den soeben mitgetheilten Resultaten der Versuche künstlicher Verdarung erhellt, dass irgend ein wesentlicher Unterschied zwischen der gekochten und ungekochten Milch nicht wahrnehmbar ist. Mit der grössten Bestimmtheit muss ich insbesondere auch betonen, dass die Gerinnung, welche beim Beginne der Einwirkung der Verdauungsfliissigkeit eintritt, bei beiden Milcharten eine und dieselbe ist. Hat anhaltende Ueberhitzung einen Einfluss anf die Natur des Käsestoffs, macht sie denselben ähnlich dem der Frauenmilch, so muss dies doch bei einer einstiundigen Ueberhitzung auf $120^{\circ} \mathrm{C}$. zur Geltung kommen. Die soweit erhitzte Milch zeigte aber keine Modification ihres Käsestoffs nach der fraglichen Richtung hin.

Mit den Ergebnissen meiner Versuche künstlicher Verdauung stimmen aber ïberein die Resultate, welche ich friher bei Versuchen an dem gastrotomirten Knaben Kröger gewonnen hatte. Allerdings wurde nur die Verdauung roher. Milch mit derjenigen gewöhnlich gekochter, nicht andauernd gekochter oder iberhitzter verglichen. Hierbei aber zeigte sich auf's Allerdeutlichste, dass die initiale Gerinnung bei beiden Arten der Mileh in der nämlichen Weise sich einstellte, und dass auch die Zeit, zu welcher dieselbe erfolgte, nicht differirte.

Trotzdem wird das Kochen der Milch rom Standpunkte der Diätetik dringend empfohlen werden mïssen. Es macht ja die Milch haltbarer und vernichtet Fermente, Gährungserreger, sowie Infectionskeime ${ }^{1}$; $o b$ alle und schon bei einmaligem kurzen Anfsieden, ist allerdings noch die Frage. Dieselbe $z \mathfrak{u}$ entscheiden, will ich hier nicht unternehmen; nur möchte ich nicht unerwähnt

1) Ganz sicher wird das Ferment der sauren Gährung und der Infectionsstoff der Maul- und Klauenseuche schon durch einfaches Aufsieden zerstört. 
lassen, dass die Vernichtung der Gährungserreger durch Kochen indirect auch die Verdaung der Milch zu fördern vermag.

\section{Buttermileh.}

Buttermilch enthält bekanntlich sämmtliche Bestandtheile der Kuhmileh, doch in anderem Verbältniss, als diese; ansserdem ist in ihr ein Theil des Zuckers in Milchsäure übergegangen. Ihre Zusammensetzung ist nach Kön ig $\left.{ }^{1}\right)$ im Mittel $=3,78 \%$ Protein, $1,25 \%$ Fett, 3,38\% Milchzucker, 0,32\% Milchsäure und 0,65\% Salze. Den Käsestoff hat sie nicht gelöst, sondern in Form feiner Gerinnselchen. IhrVerbalten gegen Säure und gegen künstlichen Magensaft ist ein wesentlich anderes, als das der frischen oder gekochten Milch.

Setzt man zu Buttermileh 2\% oder 1\% Salzsäure, so erzielt man beikeinem Mischungsverhältniss dickflockige Gerinnung. Man nimmt sogar nicht die geringste Aenderung in dem äusseren Verhalten der feinen Gerinnselchen wahr. Selbst bei Zusatz von concentrirter Salzsäure, auch von concentrirter Schwefelsäure, entstehen keine derben Coagula. Die blosse Anwesenheit bzw. Einwirkung der Milchsäure kann als Ursache nicht angesehen werden. Wird eine $0,2 \%$ Lösung derselben zu frischer Milch gesetzt, so ruft concentrirte Salzsäure in letzterer unter allen Umständen derbe Gerinnung hervor. Man wird demnach die mechanische Bearbeitung des Käsestoffs bei dem Buttern und die Einwirkung von Fermenten als Ursache jener eigenthümlichen Erscheinung betrachten dürfen. Dafür, dass auch die Fermente ihren Einfluss auf das Caseïn ausgeiubt haben, spricht entschieden der Umstand, dass im. Filtrate der Buttermilch ein grösseres Quantum an Pepton und Neutralisationspräcipitat, als in frischer Milch nachzuweisen ist. Filtrirt man nämlich Buttermilch, so erhält man eine ganz klare Flüssigkeit, in der Kochen Truibung hervorruft. Filtrirt man diese ab, so erzeugt in dem nunmehrigen klaren Filtrate Neutralisation mit Kalilauge ziemlich erhebliche Trîbung. Filtrirt man aufs Nene, so erzeugt Phosphorwolframsäure, Aleobol absol. sehr beträchtlichen Niederschlag, Kali und Kupfersulphat deutlich violette Färbung.

1) König, Die menschlichen Nahrungs- und Genussmittel. 1882. 2. S. 226 . 
Bringt man Buttermilch mit dem gleichen Volumen 2\% Salzsäure und der entsprechenden Menge Pepsin in Verdauungswärme, so bilden sich nach einigen Minuten etwas umfangreichere, aber durchaus nicht consistentere Gerinnselchen, als in der Buttermilch von vornherein sich finden. Die Gerinuselchen behalten auch fernerhin ihre grosse Lockerheit, ballen sich nirgends zusammen und lösen sich relativ rasch und ziemlich vollständig auf. Bei einem Versuche kïnstlicher Verdauung von $50 \mathrm{ccm}$ einer $3,05 \%$ Proteïn enthaltenden Buttermilch fand ich nach 4 Stunden nur noch 0,390 unverdautes Proteïn, so dass ca. $88 \%$ verdaut worden waren.

$\mathrm{Ob}$ bei natïrlicher Verdauung eine Zusammenballung des Caseïns der Buttermilch Statt hat, wie behauptet wird, ist mir sehr zweifelhaft. Ich habe regelmässig hierauf geachtet, wenn nach dem Genusse von Buttermilch erbrochen wurde, doch eine derartige Beobachtung des Zusammenballens niemals machen können.

Man wird hiernach vollberechtigt sein, die Buttermilch als Nahrungsmittel zu empfehlen. Allerdings darf dies nicht bedingungslos geschehen. Der Gehalt an Milchsäure, so angenehm er dem Geschmacke ist, bedingt doch bei vielen Individuen, zumal bei kleinen Kindern, leicht Colikschmerzen, sowie Durchfälle. Man wird die Buttermilch deshalb Säuglingen unter keinen Umständen reichen dürfen. Ich weiss, dass auch dies selbst von Aerzten empfohlen worden ist. Ballot rïhmte eine Mischung von Buttermilch mit Weizenmehl und Zucker einige Minuten gekocht und behauptete, sie bei seinen eigenen Kindern mit Erfolg angewandt zu haben. Gleiches meldete Mansveld. Aber ihre Empfehlungen haben die allgemeine Ansicht beziiglich der schädigenden Wirkung dieses Nahrungsmittels im Säuglingsalter nicht zu erschüttern vermocht. Grösseren Kindern und Erwachsenen wird man dasselbe gern gestatten, es eventuell sogar anrathen, wenn sie es vertragen, d. h. weder Leibschmerzen noch Durchfälle nach dem Genusse bekommen. Von grossem Belange ist da allerdings die Menge der in der Buttermilch vorhandenen Säuren. Findet sich von letzterer nicht mehr als $0,25-0,3$, so stellen sich in der Regel jene Verdaungsbeschwerden nicht ein.

Man kann aber die Säure in der Buttermilch abstumpfen, am besten durch Kalkwasser. Ist die Menge der Säure eine mitt- 
lere, so gentigt es in der Regel, anf 2 Th. der Buttermilch reichlich $1 \mathrm{Th}$. jenes Wassers zuzusetzen, um neutrale Reaction zu erzielen. Dieser Zusatz ruft erst kurz vor der völligen Neutralisirung etwas grössere Flocken hervor; doch sind dieselben auch jetzt entschieden sehr locker. Gibt man zu der Kalkwasser-Buttermilch etwas Zucker, so hat man ein angenehm schmeckendes, leicht verdauliches, weder Colikschmerzen, noch Durchfälle erzeugendes Nahrungsmittel. Bringt man diese Nahrung mit künstlichem Magensaft von 3\%o Säure zur Verdauung, so entstehen weder im Beginn, noch im weiteren Verlaufe derbe Coagula. Die Flocken sind und bleiben locker, lösen sich auch entschieden vollständiger und rascher auf, als bei Verwendung von Milch und Kalkwasser.

\section{Die Methoden, die Verdanlichkeit der Kuhmilch za erhöhen.}

Bedenkt man, dass in der Norm von Kindern des ersten Jahres die Kuhmileh zu $92-94 \%$ ausgenutzt wird, so könnte es scheinen, als sei es überflïssig, nach Mitteln zu suchen, um ihre Verdaulichkeit zu erhöhen. Und doch ist dies nöthig. Denn die Kuhmilch wird keineswegs von allen Säuglingen so gut verdaut und gibt gerade deshalb bei vielen derselben Anlass zu acuten und chronischen Gesundheitsstörungen verschiedener Art. Auch sollte nicht vergessen werden, dass selbst jenes normale Maass der Ausnutzung hinter demjenigen der Ausnutzung der Mattermilch noch immer nicht unerheblich zurückbleibt, eine Thatsache, welche schon für sich ein Sporn sein muss, Mittel zur Erhöhung der Verdaulichkeit ausfindig zu machen. Dazu kommt, dass die Kuhmileh von Erwachsenen und wahrscheinlich auch schon von grösseren Kindern noch weniger gut ansgentitzt wird. Von Rindfleisch gehen bei ihnen nur $4-5 \%$, von Weizenbrot dieselbe Menge, von der Kuhmilch dagegen ca. 10\% unverdat wieder ab. Die Frage der Erhöhung ihrer Verdaulichkeit ist demnach in der That von hohem praktischen Interesse. Sie würde im Wesentlichen gelöst sein, wenn es gelänge, das Kuhmilchcaseïn völlig in Frauenmilchcasein umzuwandeln, ohne im Uebrigen die Composition der Milch und den Geschmack derselben zu ändern. So lange dies nicht erreicht ist, müssen wir mit weniger radicalen Methoden zufrieden sein, die uns dem Ziele mindestens näher führen. 
Eine Steigerung der Verdaulichkeit der Kuhmilch darf von allen Mitteln erwartet werden, welche eine weniger dickliche und consistente Gerinnung derselben bei der ersten Einwirkung des Magensaftes zu Wege bringen. Denn dann werden sowohl das Caseïn, als das Fett und die Salze leichter von sämmtlichen Verdauungssäften angegriffen werden können. Die Verdaulichkeit wird aber zweifellos erhöht werden auch durch Unsehädlichmachung der Gährungserreger, die in der Kuhmilch stets sich finden und durch Erzeugung von Säuren ungünstig auf den Verlauf der Digestion bezw. der Ausuutzung einwirken. Da das Kochen der Milch jene Unschädlichmachung zur Folge hat, und.in Bezug auf diese Wirkung sehon besprochen ist, so wird es sich für uns im Wesentlichen nur um die Mittel handeln, welche nach der zuerst bezeichneten Richtung hin wirken.

Um eine weniger dicke Gerinnung der Milch bei der Verdauung zu erzielen, hat man die verschiedenartigsten Zusätze gemacht. Es sind im Wesentlichen die folgenden vorgeschlagen worden:

1) Wasser;

2) Abkochungen von Getreidemehlen, auch von Salepwurzel and Arrowroot;

3) Malzextract;

4) Gummi arabicum;

5) Gelatinelösungen und Gelatine-haltige Flüssigkeiten;

6) Eigelb;

7) Gewisse Salze und Kalkwasser, sowie Alkalien;

8) Milchzucker.

9) Zusatz von Wasser.

Schon a priori muss es als nicht unwahrscheinlich betrachtet werden, dass eine mit Wasser verdünnte Milch auch weniger consistente Gerinnsel zeigt, zumal wenn es richtig ist, dass auf die Derbheit der Ausfällung die relative Menge von Kalkphosphat einen bestimmenden Einfluss ausübt ${ }^{1}$ ). Das Experiment ergibt nun Folgendes :

Auch noch bei einer starken Verdünnung der Kuhmileb mit Wasser, bei einem Verhältniss von 1 Theil der ersteren zu 3

1) Vergl. darüber auch Hammarsten: Zur Kenntniss des Caseïns und der Wirkung des Labfermentes. Nova Acta R. S. Sc. Upsaliensis. 1877. 
Theilen des letzteren, ist auf Zusatz verdïnnter Salzsäure käsigweisse Gerinnung in umfangreichen Flocken zu constatiren. Nur ballen sich diese nicht mehr zu derberen Kuchen zusammen, wie dies bei der unverdünnten Milch Statt findet. Setzt man zu einer, im eben angegebenen Verhältniss verdünnten Milch so viel künstlichen Magensaft, dass käsig-flockige Ausfällung eintritt, und bringt man nun die Mischung in eine Temperatur von $40^{\circ} \mathrm{C}$., so bildet sich wiederum kein festes Coagulum; die Gerinnselchen bleiben vielmehr nur in lockerem Zusammenhange, wie man dies beim leichten Bewegen des Gefässes sofort erkennt. Deshalb ist auch die Ausnutzung solcher Mischung eine etwas bessere, als die der unverdünnten Milch.

Es gaben bei künstlicher Verdauung mit Pepsin in $41 / 2$ Stunden $50 \mathrm{cem}$ unverdünnter Kuhmilch $=1,524 \mathrm{gr}$ Pepton.

Aus $50 \mathrm{ccm}$ der mit dem Dreifachen ihres Volumens Wasser verdünnten Milch der nämlichen Beschaffenheit und Zusammensetzung erhielt ich bei Anwendung der gleichen Menge verdünnter Salzsäure in der nämlichen Zeit
1) 1,588 Pepton,
2) 1,607
3) 1,601

d. h. im Durchschnitt $=1,598$ Pepton oder fast $5 \%$ Pepton mebr, als aus unverdünnter Milch.

2) Ausser Wasser kommen in Frage die schleimigen Abkochungen von Getreidemehlen, von Gerstenmehl, Hafermehl, von Maizena, und die Abkochungen von Salepwurzel, bzw. von Arrowroot. Von ihnen allen nimmt man an, dass sie die Kuhmilch deshalb leichter verdaulich machen, weil sie rein mechanisch eine Gerinnung derselben in derbere und grössere Klümpchen verhindern. Sehen wir zu, ob dies richtig ist und $o b$ die Verdaulichkeit der Kuhmileh durch diese Zusätze in der That zunimmt.

Versetzt man Kuhmilch mit dem dritten Theile gewöhnlichen, etwa aus 5:100 Wasser bereiteten Gerstenschleimes, oder mit ebensoviel Haferschleim, so entsteht auf Hinzufïgung von künstlichem Magensafte mit 2\% Salzsäure je nach der Menge der letzteren entwederkeine, oder eine feine staubartige, oder eine flockige Ausfällung, wie bei unvermischter Mileh. Aber entsteht eine flockige Ausfällung, so bildet dieselbe keine consistenten, sich zusammenballenden Coagula, auch dann nicht, wenn man sie ohne Schtitteln ruhig 
stehen lässt. Bringt man solche Mischung, in der flockige Gerinnsel sich zeigen, in eine Wärme von $40^{\circ} \mathrm{C}$., so entstehen auch dann in keinem Stadium der Verdauung dickliche Klumpen, vielmehr finden wir eine Flïssigkeit, welche an Consistenz etwa einer Milchgriessuppe gleicht. Die Peptonisirung erfolgt auch ein wenig vollständiger, als wenn unvermisehte oder mit $1 / 3$ Wasser verdünnte Kuhmilch zur Verdaung gestellt wird.

Es gaben $50 \mathrm{ccm}$ Kuhmilch und $25 \mathrm{ccm}$ Wasser mit $50 \mathrm{ccm}$ eines Verdauungssaftes von 2,5\% Salzsäure $=1,668$ Pepton. Es gaben $50 \mathrm{ccm}$ derselben Milch und $25 \mathrm{ccm}$ Gerstenschleim mit 50 cem eines Verdauungssaftes von 2,5\% Salzsäure in gleicher Zeit ( $4 \frac{1}{2}$ Stunde)
1) 1,829 Pepton,
2) 1,807 "

Einen Antheil am Plus der Peptonmenge haben wir allerdings auf den Mehrgehalt der Gerstenschleim enthaltenden Mischung an Eiweiss zu setzen. Da aber das Eiweiss des Schleimes für sich nur 0,130 beträgt, das Plus an Pepton aber in dem einen Falle 0,161, so liegt selbst für den Fall, dass sämmtliches Eiweiss des Schleimes peptonisirt worden wäre, noeh eine ausgiebigere Peptonisirung der Milch vor.

Von grösserem Werthe erscheint aber das Studium der Ausnutzung dieser schleimhaltigen Mischung am Menschen selbst.

1. Der Knabe Leo M. erhielt von der 12. Lebenswoche an Kuhmilch und Gerstenschleim im Verhältniss von 2:1 und nahm davon täglich $=1000,0 \mathrm{ccm}$ mit 27,5 Eiweiss, 25,8 Fett, 3,9 Salzen und 23,5 Zucker.

Die Menge der täglichen Fäces betrug im Mittel $=29,0$ mit einer Trockensubstanz von 5,42.

In Ietzterer befanden sich Eiweiss zu 0,071 .

$$
\begin{array}{llc}
\text { Fett } & \text { zu } & 0,878 . \\
\text { Salze } & \text { zu } & 1,643 . \\
\text { Zucker } & \text { zu } & 0 .
\end{array}
$$

Es waren demnach ausgenutzt das Eiweiss zu $99,75 \%$.

$$
\begin{array}{ll}
\text { das Fett } & \text { zu } 96,6 \% \text {. } \\
\text { die Salze } & \text { zu } 57 \% \text {. } \\
\text { der Zucker } & \text { zu } 100 \% \text {. }
\end{array}
$$

Das Eiweiss war also nahezu vollständig, das Fett entschieden 
besser und die Salze etwas besser ausgenutzt, als bei Darreichung von Milch oder mit Wasser verdünnter Milch.

2. S. W., ein gut entwickelter Knabe von 10 Monaten erhielt während der 3 Tage meiner Untersuchung regelmässig binnen 24 Stunden $=1500 \mathrm{ccm}$ Kuhmilch nebst beigemischten $400 \mathrm{ccm}$ Griesschleim, der ans 30,0 Gries bereitet war.

Die Entleerungen erfolgten täglich im durchschnittlichen Gewicht von 60,5 .

Bei der Untersuchung fand ich folgendes:
1. am 4./9. $1880=$ Fäces
5,000 .
Trockensubstanz 0,693, in ihr
Fett 0,079 , d. h. $11,5 \%$
2. $\operatorname{am} 6 . / 9 \cdot 1880=$ Fäces 7,340 .
Trockensubstanz 1,123 , in ihr
Fett 0,116 , d. h. $10,4 \%$.
3. am $8 . / 9 \cdot 1880=$ Fäces 6,900 .
Trockensubstanz 1,041, in ihr Fett 0,112 , d. h. $10,8 \%$.

Die dem Kinde gereichte Milch war fettarm; sie enthielt nur 2,3\%-2,8\% Fett. Berechnet man den mittleren Fettgehalt mit $2,5 \%$, so erhielt das Kind in dem Tagesquantum von 1500,0 Milch $=37,5$ Fett. In 60,5 Fäces war im Durchschnitt aus obigen Feststellungen enthalten an Fett $=0,989$. Darnach war das eingeführte Quantum Fett verdaut worden zu 97,4\%. Es ist das eine vorzuigliche Ausnutzung, welche derjenigen des Fettes der Muttermilch ganz nahe kommt.

Die Untersuchung hat sich in diesem letzteren Falle allerdings blos auf die Fette bezogen. Wir sind aber zweifellos berechtigt, anzunehmen, dass der besseren Verdaunng derselben auch eine solche der übrigen Nährstoffe parallel gegangen sei. Ueberdies lehrt ja die Erfahrung, dass Säuglinge, welche Kuhmilch, auch verdünnte, nicht vertragen, sehr oft die mit Gerstenschleim versetzte leicht verdauen, normale Entleerungen nach derselben zeigen und gut bei derselben gedeihen.

Wesentliche Unterschiede zwischen Zusatz von Gerstenschleim und demjenigen von Haferschleim, Abkochung von Arrowroot, von Maizena giebt es nicht, wenigstens nicht bei künstlicher Verdauung.

Stellt man letztere bei diesen Mischungen unter gleichzeitigem 
Zusatze von Speichel an, so wird das Resultat nur wenig alterirt. Man beobachtet in solchem Falle, dass etwa nach viertelstündiger Einwirkung der Verdaungssäfte die Caseïnflocken hie und da dureh Aneinanderlagerung an Umfang zunehmen, aber ein $\mathrm{Zu}-$ sammenballen zu grossen Coagulis findet doeh nicht Statt. Die Art der initialen Gerinnung bleibt also auch nach Speichelzusatz für den ferneren Ablauf der Verdaunng maassgebend.

3) Zusatz von Malzextract. Dieser Zusatz ist gleichfalls empfohlen worden, um die Kuhmilch leichter verdaulich zu machen. Setzt man zu $30 \mathrm{cem}$ derselben 3,0 Malzextract, so bekommt man eine schwach gelblich aussehende Flüssigkeit von stark süssem Geschmacke und hohem specif. Gewichte (1095). Giesst man von dieser Mischung vorsichtig unter Schütteln in $10 \mathrm{ccm}$ einer $2 \%$ Salzsäurelösung, so entsteht schon mit den letzten Tropfen des sechsten ecm der Mischung eine Ausfällung, die dünnflockig, beim weiteren Zugiessen ziemlich dickflockig wird. Mischt man $30 \mathrm{ccm}$ Milch mit 3,0 Malzextract und $30 \mathrm{ccm}$ einer Verdauungsfliussigkeit von $2 \%$ Salzsäure, so findet eine Auställung Statt, die nur wenig dünnflockiger ist, als wenn man unverdünnte Milch verwendet. Setzt man dann die Masse zur Verdauang hin, so entstehen nach wenigen Minuten etwas umfangreichere Gerinnsel, doch keine grossen Coagula. Die Aufösung derselben erfolgt nicht rascher and nicht vollständiger, als wenn man Milch mit Gerstenschleim gemischt verwendet.

4) Zusatz von Gummi arabicum. Versetzt man Kuhmilch mit Mucilago G. arabici, etwa $30 \mathrm{ccm}$ der ersteren mit $15 \mathrm{cem}$ der letzteren, so erhält man, falls die Milch von vornherein amphoter reagirte, eine säuerliche Mischung, da auch frischer Gummischleim sauer reagirt. Wenn man nun obige $45 \mathrm{ccm}$ mit $30 \mathrm{ccm}$ einer $2 \%$ Salzsäurelösung vermischt, so bildet sich eine dünnflockige Ausfallung. Die letztere ist auch bei anderen Mischungsverhältnissen relativ dünnflockig; derbe, sich zusammenballende Coagula erscheinen nicht. Andrerseits findet man durchaus keine so dünne Gerinnung, wie bei Frauenmilch, immerhin aber eine dünnere, als wenn man eine nach obigem Verhältniss mit Wasser versetzte Milch verwandt hätte.

Fügt man nun der Mischung von $30 \mathrm{cem}$ Milch und $15 \mathrm{ccm}$ Mucilago G. arab. und $30 \mathrm{ccm}$ Salzsäurelösung noch 0,25 Pepsin hinzu und stellt sie dann zur Digestion, so bilden sich wohl, 
falls gar nicht geschüttelt wird, etwas grössere Flocken, in Allgemeinen aber bleiben diese viel kleiner und lockerer, als bei unvermischter oder mit Wasser verdünnter Kuhmilch. Auch die Peptonisirung der mit Gummi arabicum versetzten Kuhmilch ist eine etwas ausgiebigere.

Ich stellte $25 \mathrm{ccm}$ Kuhmilch mit 12,5 Mucilago G. arab. und 30,0 eines künstlichen Magensaftes (mit 2\% Salzsäure) zur Verdaung und erzielte nach 4 Stunden an Pepton und Neutralisationspräcipat $=0,858 \mathrm{gr}$.

Gleichzeitig stellte ich andere $25 \mathrm{ccm}$ der nämlichen Milch mit 12,5 cem Wasser, darauf mit 30,0 eines künstlichen Magensafts von $2 \%$ Salzsäure zur Verdauung und erzielte nach 4 Stunden an Pepton and Neutralisationspräcipitat $=0,827 \mathrm{gr}$.

In beiden Fällen war die Menge des Netralisationspräcipitates nur geringfigigig.

Da nach meinen frïheren Feststellungen Gummi arabicum im Magen umgewandelt wird in Traubenzucker, so liesse sich gegen die Verwendung einer Mischung von Milch und jenem Zusatze Nichts einwenden. Man könnte sie sogar dringend empfehlen, wenn nicht der Gummischleim ein saurer wäre und durch die Verdaung noch saurer würde. Steht es doch fest, dass der Organismus des Säuglings, für den die Erhöhung der Verdaulichkeit der Kuhmilch ja am wichtigsten ist, auf alle organischen Süuren in unangenehmer Weise reagirt. Ein wie hoher Säuregrad aber in dem natürlich digerirten Gummi sich entwickelt, habe ich bei den Untersuchungen des gastrotomirten Knaben Kröger konstatiren können. Man wird desshalb gut thun, bei der Verwendung von Gummi in jedem Falle einen kleinen Zusatz von Natr. bicarb. zu machen.

5) Ueber den Einfluss des Zusatzes von Gelatine zur Kuhmilch habe ich folgendes constatirt.

Wenn ich von einer $5 \%$ Gelatinelösung $10 \mathrm{ccm}$ mit $20 \mathrm{ccm}$ Kuhmilch mischte und dann von dieser Mischung langsam unter Schütteln in $25 \mathrm{ccm}$ einer $2 \%$ Salzsäurelösung eingoss, so entstanden beim Zufügen von 29,5 cem der Mischung graue, feine, staubartige Flocken, wie wenn unvermischte Kuhmilch verwandt wäre. Nahm ich jedoch $30 \mathrm{ccm}$ einer eben solchen Mischung von Gelatinelösung und Kuhmilch und goss dieselbe in $16 \mathrm{cem}$ der 2\% Salzsäurelösung ein, so entstanden käsig weisse, grosse und consistente Flocken. Setzte ich die erste und zweite Probe 
nach Zugabe von Pepsin zur Verdauung hin, so zeigten sich genau dieselben Veränderungen, wie bei der Digestion von Kuhmilch ohne Zusatz von Gelatine. Allerdings schienen bei der zweiten Probe die käsig weissen Flocken im ganzen etwas lockerer, aber doch nicht viel lockerer, als wenn Kuhmilch mit dem dritten Theil Wasser zur Verdaung gestellt wird. Auch die Peptonisirung der mit Gelatine vermischten Milch ist keine bessere, als die verdünnter Mileh. Ich stellte zwei Portionen zur Verdaung hin; für beide war die nämliche Milch verwandt worden. Die erste enthielt $20 \mathrm{ccm}$ Kuhmilch mit $10 \mathrm{ccm}$ einer 3,0\% Gelatinelösung, 25,0 einer $2 \%$ Salzsäurelösung und 0,2 Pepsin, die zweite dagegen $20 \mathrm{ccm}$ Kuhmilch, $10 \mathrm{ccm}$ Wasser, 25,0 einer 2\% Salzsäurelösung and 0,2 Pepsin. Aus der ersten Portion erhielt ich an Pepton und Neutralisationspräcipitat $=0,792$, aus der zweiten, die ja anch noch das Leimpepton enthielt $=0,776$.

Man ersieht hieraus, dass die Zumischung von Gelatinelösung zur Milch doch nicht den Vortheil hat, den man ihr früher ziemlich allgemein zuzusprechen geneigt war.

6) Die Mischung von Milch und Eigelb ist von Enko 1) vorgeschlagen worden. Derselbe behauptet, dass sie nur feinflockige Gerinnung zeigt, speciell wenn der Zusatz nach folgenden Vorschriften geschehe:

1. abgerahmte Milch $1 / 2$ Flasche, Wasser 1/4 Flasche, Eigelb von 2 Eiern, Milchzucker 2 Theelöffel voll.

2. abgerahmte Milch $1 / 2$ Flasche, Eigelb von $1 \mathrm{Ei}$.

Ich habe die Mischung nach diesen Vorschriften vorgenommen und gefunden, dass sie mit gleichen Theilen $2 \%$ Salzsäure gemischt eine Ausfällung zeigt, die zwar flockig ist, aber keine grösseren sich zusammenballenden Klümpchen zeigt. Stellte ich solche salzsaure Mischung nach Zusatz von Pepsin zur Verdauung, so bildeten sich auch jetzt keine consistenteren Flocken, keine grösseren Coagula. Ich kann also die Angaben von Enko im Ganzen bestätigen, möchte nur betonen, dass die Gerinnung doch nicht so feinflockig ist, wie bei Franenmilch.

1) Petersburger medic. Wochenschrift 1880 . S. 46. 
Die Verwendung einer Mischung von Eigelb und Kuhmilch zur Eruährung von Säuglingen hat einen grossen Uebelstand im Gefolge, nämlich den schon anderweitig von mir hervorge. bobenen, dass sie fast immer starke Blähungen erzeugt, welche die Kinder ungemein quälen, im rubigen Schlafe stören. Man wird desshalb einer solchen Mischung trotz der Ergebnisse des Experimentes aus praktischen Rücksichten das Wort nicht wohl reden können.

7) Was nun endlich den Zusatz von Salzen zur Mileh betrifft, so hatte man von ihnen eine Zeitlang sich Viel versprochen. Das von Kanz za Wattwyl in den Handel gebrachte Laetin, ein im Wesentlichen aus Milchzucker bestehendes und ausserdem noch die Salze der Molken enthaltendes Pulver sollte die Gerinnung der Kubmilch zu einer feinflockigen machen, die Verdaulichleeit derselben ausserordentlich erhöhen. Günstiges berichteten über diesen Zusatz Albrecht und Camerer; insbesondere fand letzterer, dass das Lactin die Kuhmilch so feinflockig wie Frauenmilch gerinnen mache. -- Jingsthin hat aber Pfe iffer ${ }^{1}$ ) gerade das Gegentheil constatirt; er sprach sich dahin aus, dass der Z $\mathbb{Z}^{-}$ satz jenes Pulvers das Verhalten der Kuhmilch weder gegen verdinnte Salzsäure, noch gegen Pepsinsalzsäure irgendwie verändere. Gleiches behauptete er von dem Paulcke'schen Salze, das ebenfalls aus Milchzucker und bestimmten Salzen besteht, und von dem der Erfinder mit grosser Bestimmtheit angiebt, dass es die Caseïnansscheidung in der Kuhmilch äusserst feinflockig mache.

Ich habe mit beiden Pulvern zahlreiche Versuche angestellt, genau in der Weise, wie es $\mathrm{Kunz}$ bzw. Paulcke fordern, und kann den P feiffer'schen Ausspruch nur bestätigen.

Kunz giebt folgende Gebranchsanweisung:

Mán nehme 1 Portion Lactin $=12,5 \mathrm{gr}$, dazu

3 Trinkglas Milch $=600$ "

$1 / 2$ Trinkglas Wasser $=100 \quad n$

oder fuir Kinder von mehr als 3 Monat

1 Portion Lactin $=12,5 \mathrm{gr}$, dazu

2 Trinkglas Milch $=400$ "

1 Trinkglas Wasser $=100$ "

In beiden Fällen ist die Mischung zu kochen.

1) E. Pfeiffer in Berliner kl. Woehenschrift 1881. Nr. 35. 
Wenn man nach diesen Vorschriften verfährt und nun von der Mischung beispielsweise 25,0 in 25,0 einer 2\% Salzsäurelösung bringt, so entsteht jedesmal eine dickflockige, käsig-weisse Ausfällung, auch wenn die Zumischung eine ganz langsame ist und unter häufigem Schütteln vorgenommen wird. Wie wenig überbaupt Lactin die Gerinnung der Kuhmileh zu einer feinflockigen za machen im Stande ist, geht sehr schön aus folgendem Versuche hervor:

Man nehme 10,0 einer 2\% Salzsäurelösung, setze langsam und unter Schïtteln 7,5 einer amphoter reagirenden Kuhmilch hinzu. In der Regel zeigt sich noch keine Ausfällung, höchstens eine ganz schwach staubartige. Jetzt nehme man, 0,20 Lactin und sofort wird man eine dicke Gerinnung sich bilden sehen, die so dickflockig ist, wie sie nur sein kann.

Paulcke fordert, dass sein Salz in folgender Weise gebraucht werde:

Eine Portion zu 12,0 ist in 250,0 heissen Wassers zu lösen and diese Lösung ist beispielsweise für Kinder von 2 Monaten mit 500,0 Kuhmilch zu misehen. Eine solche Mischung soll nach ihm mit Labzusatz bei $37^{\circ} \mathrm{C}$. hingestellt nach $7 \frac{1}{2}$ Minuten Coagulirung zeigen; das ausgeschiedene Caseïn soll aber wenig zusammenhängend, beim Umschiitteln in leichte Flocken sich zertheilen. Ja, bei einer Mischung von gleichen Theilen Milch und Milchsalzlösung will Paulcke nach Zugabe von Lab beobachtet haben, dass das Caseïn, ohne abzusetzen, äusserst feinflockig vertheilt blieb und dass die Reaction alkalisch war.

Ich kann, wie schon gesagt, auch von diesem Salze nichts Günstiges berichten. Wenn man eine Mischung von gleichen Theilen Milch und Milchsalzlösung nach Paulcke's Vorschrift sich bereitet, und von dieser $20 \mathrm{~cm}$ mit 10,0 einer $2 \%$ Salzsäure versetzt, so entsteht sofort eine stark käsige, derbflockige Ausfällung. Wenn man nun Pepsin hinzugiebt und die ganze Mischung zur Digestion binstellt, so zeigt sich, dass die Flocken gar kein anderes Aussehen bieten and nicht anders sich verhalten, als wenn man Milch mit gleichen Theilen Wasser und dann mit Verdauungsflïssigkeit vermischt zur Digestion hinstellt.

Wenn man $50 \mathrm{cem}$ Kuhmilch mit 1,25 Paulcke's Salz erhitzt, nach dem Erkalten 50,0 Verdauungsflüssigkeit von $2 \%$ Salzsäure und 0,4 Pepsin hinzugiebt und die Masse nunmehr einer Temperatur von $40^{\circ} \mathrm{C}$. aussetzt, so entsteht eine deutliche Aus- 
fällung, die sich zusammenballt, beim Schütteln sich wieder in einzelne kleinere Gerinnsel zertheilt. Von einer feinflockigen Coagulation kann absolut nicht die Rede sein. Das Paulcke'sche Salz bietet also nicht den behaupteten Vortheil.

Man hat auch gesagt, dass der Zusatz des gewöhnlichen Kochsalzes zur Kuhmilch die feste Gerinnung derselbea durch Lab verzögere, erschwere oder ganz unmöglich mache. Der Vertheidiger dieser Ansicht war A. Schmidt1), welcher auf Grund eigener Versuche aussprach, dass alle Alkalisalze, insbesondere Chlornatrium and Chlorkalium die Labgerinnung stören sollten, während sie gerade umgekehrt für die Fibringerinnung ein nothwendiges Bedürfniss seien. Aber schon Hammarsten, welcher das Verhalten des Chlornatriums bezüglich seines Einflusses auf die Gerinnung der Milch durch Lab einer Prïfung unterzog, fand, dass es nur in sehr geringfügigem Grade diese Gerinnung verzögert, ja dass es dieselbe sogar entschieden befördert, wenn etwas Wasser zur Milch gesetzt wird. Diese Angaben kann ich in vollem Umfange bestätigen. Doch ist das Verhalten der mit Kochsalz versetaten Milch bei der Gerinnung durch Lab für uns von nicht so grossem Belange, da wir aus demselben keine Schlüsse bezüglich des Verhaltens im mensehlichen Magen ziehen können. Man hat dies voreilig gethan, aber mit grossem Unrecht. Es musste geprüft werden wie eine mit Kochsalz versetzte Wilch bei Gegenwart von verdünnter Salzsäure und Pepsin in der Verdauungswärme sich verändert.

Versetzt man 7,5 ccm Milch mit ebenso viel destillirtem Wasser, so kann man diese $15,0 \mathrm{ccm}$ langsam unter Schütteln $\mathrm{zu} 10,0 \mathrm{~cm}$ einer $2 \%$ Salzsäure zumischen, ohne dass der Regel nach überhaupt eine Ausfällung zu Tage tritt. Sobald man nun aber einige wenige Körnchen Kochsalz in die Mischung bringt, entsteht sofort eine käsig flockige Gerinnung.

Bringt man eine Mischung von 7,0 cem Milch und 10,0 einer $2 \%$ Salzsäure nebst Pepsin in Verdauungswärme, so bildet sich nach 7-10 Minuten eine graue, zarte Ausfällung. Dieselbe wird aber sofort dickflockig, käsig-weiss, wenn man in die Mischung ein wenig Kochsalzlösung bringt and umschiittelt.

Aus diesen beiden Versuchen geht hervor, dass das Kochsalz auf die Art der initialen Gerinnung durch künstlichen Magensaft nicht den günstigen Einfluss ausiibt, von dem man gesprochen

1) Pflüger's Archiv XIII. S. 93 und XI. S. 1 ff. 
hat. Dass es trotzdem unter Umständen, z. B. bei mangelnder Secretion des Magens, günstig zu wirken vermag, soll gar nicht bestritten werden.

Sehr Viele glauben, dass Kalk wasserzusatz zur Kuhmilch die letztere besonders leicht verdaulich mache und verordnen ihn desshalb sowohl Säuglingen, als auch kranken Individuen, speciell magenleidenden. Dem gegenïber muss aber betont werden, dass das Experiment die leichtere Verdaulichkeit auch dieser Mischung nicht zeigt. Die Ausfällang der Kalkwassermilch durch verdünnte Salzsäure bzw. kiunstlichen Magensaft ist keineswegs eine weniger dickflockige, als die einer mit Wasser verdünnten Milch. Der einzige Unterschied besteht darin, dass bei der erstgenannten Mischung mehr Säure zur Ausfällung erforderlich wird, als bei der letztgenannten.

Versetzt man frische, amphoter reagirende Kuhmilch mit der Hälfte ihres Volumens Kalkwasser - ein solches Verhältniss (2:1) wird in praxi meist verordnet - so erseheint käsig-weisse Gerinnung, sobald man von dieser Mischung den zehnten ccm in $10 \mathrm{ccm}$ einer $2 \%$ Salzsäure eingiesst, nachđem man vorher nean ecm langsam und unter Schütteln eingoss.

Aus einer Mischung von $25 \mathrm{ccm}$ einer Kuhmilch, die 4,41\% Proteïn enthielt, und 12,5 cem Kalkwasser, die ich mit $36 \mathrm{ccm}$ einer $2 \%$ Salzsäure und 0,25 Pepsin zur Verdauung stellte, gewann ich an Pepton $=0,778$, ca. $70 \%$ des Proteïn. Ein wesentlicher Untersehied in der Peptonisirung dieser Misehung and einer mit dem dritten Theil Wasser verdiunten Milch ist also nicht zu constatiren gewesen.

Damit steht es keineswegs in Widerspruch, dass thatsächlich unter Umständen die Kalkwassermilch viel besser verdaut wird, als die einfach mit Wasser versetzte oder als unverdünnte Milch. Wenn nämlich eine abnorme Säurebildung im Verdauungstractus Statt hat, so wird das Kalkwasser als Absorbens günstig wirken. Es lassen sich aber andrerseits auch Fälle denken, in denen eine solche Kalkwassermilch eher weniger gut verdaut wird, als gewöhnliche. Dies ist a priori zu präsumiren, wenn aus irgend welchem Grunde ein säurearmer Magensaft zur Absonderung gelangt.

Ebenso wenig wie der Zusatz von Kalkwasser vermag derjenige von irgend einem Alkali, von Natronlauge, kohlensaurem Natron, kohlensaurem Kali die Kuhmilch só zu ver- 
ändern, dass sie allemal auf Beimischung von verdünnter Salzsäure oder von künstlichem Magensaft feinflockig gerinnt. Ein einfacher Versuch wird dies bestätigen. Man gebe zur Kuhmilch eine Lösung von kohlensaurem Natron bis zu deutlich alkalischer Reaction und füge dann successive kleine Mengen von 2\% Salzsäure hinzu. Es wird nach Zusatz eines gewissen Quantums flockige Ausfällung eintreten, wie bei gewöhnlicher Kuhmileh. Erst wenn man dann die Zugabe von Salzsäure steigert und schüttelt, beginnen die Flocken wieder zu schwinden. - Man könnte vielleicht auch glauben, dass längeres Stehenlassen der Milch mit einem Alkali, z. B. mit Natronlauge, sie so verändere, dass sie weniger dick durch kïnstlichen Magensaft gerinne; doch ist auch dies nicht der Fall.

8) Zusatz von Milchzucker ist gleichfalls ohne Einfluss auf die Art der Gerinnung. Man kann die Kuhmilch noch ïber das bei der Ernährung von Kindern zulässige Maass mit jenem Zucker versetzen und wird bei Zumischung von $2 \%$ Salzsäure oder von Verdauungsflüssigkeit mit 2\% Salzsäure in der Ausfällung bzw. in dem Grade der Peptonisirung keine wesentlichen Unterschiede von dem Verhalten solcher Kubmilch wahrnehmen, der man keinen Milchzucker zumischte. Bringt man $50 \mathrm{~cm}$ einer Verdaunngsfluissigkeit (mit 2\% Salzsäure) und $50 \mathrm{ccm}$ einer mit 2,5 Milchzucker versetzten Milch zusammen, so entsteht ganz zweifellos ebenso dickflockige Ausfällung, als wäre kein Milchzucker zugesetzt.

Anderweitige Mittel, die Verdaulichkeit der Kuhmilch zu erhöhen.

Ziemlich allgemein gilt verdünter Alkohol, z. B. Cognac, der ja etwa $60 \%$ Alkohol enthält, für ein vorzügliches Mittel, die Verdaulichkeit der Kuhmilch zu erhöhen, wenn letztere mit ihm vermischt genossen wird. Notoriseh ist auch, dass sebr Viele, welche Kuhmilch für sich nicht gut vertragen, sie ohne jede Beschwerde verdauen, sobald sie mit etwa $5,0-7,5-10,0$ Cognac auf 100,0 versetzt wurde. Aber das Experiment lässt noch nicht erkennen, wodurch dies bedingt ist. Mischt man $25 \mathrm{ccm}$ Milch mit 3,5 eines $60 \%$ Alkohol, so findet man bei sehr scharfem Zusehen eine äusserst feine Ausfällung. Fügt man dann $25 \mathrm{ccm}$ einer $2 \%$ Salzsäure zu, so entsteht alsbald flockige Ausfällung, die derber 
und deutlicher wird, wenn man noch $1 \mathrm{ccm}$ Milch hinzngiesst. Bringt man nunmehr 0,25 Pepsin in die Masse und diese alsdann in eine gleichmässige Temperatur von $400^{\circ} \mathrm{C}$, so bilden sich ebenso dicke Coagula, als wenn gleiche Mengen Milch und Verdaungsflüssigkeit von $2 \%$ Salzsänre-Gehalt gemischt und zur Digestion hingestellt worden wären. Auch eine raschere oder vollständigere Peptonisirung kounte ich in der alkoholischen Mileh nicht constatiren. Wenn eine solche trotzdem im menschlichen Digestionstractus besser verdant wird, so liegt der Grund wahrscheinlich in der, durch den Gehalt an Alkohol hervorgerufenen Steigerung der Labdrüsensekretion, möglicherweise auch in der Unschädlichmachung von Gäbrungserregern in der Milch.

Man hat auch behauptet, dass die Gerinnungsfähigkeit der Milch durch längere Di aly s e herabgesetzt, ja ganz aufgehoben werden könne ${ }^{1}$ ). Ist dies richtig, so liegt es nahe, dialysirte Milch für leichter verdaulich zu halten. Dem scheint aber nicht so zu sein. Ich kann allerdings bestätigen, dass die Gerinnungsfähigkeit der Milch dureh Lab nach hinreichend langer Dialyse ganz oder nahezu ganz verschwindet. Aber, wenn ich solche dialysirte Milch mit $2 \%$ Salzsäure oder mit Verdaunngsflüssigkeit behandelte, welche $2 \%$ Salzsäure enthält, so bildeten sich Gerinnsel geradeso und keineswegs dünner, als bei gewöhnlicher Milch. Auch erfolgte die Peptonisirung der dialysirten keineswegs rascher.

Es bleibt noch übrig, die Kuhmilch behufs leichterer Verdaulichkeit zu peptonisiren. Dies kann geschehen, wie es oben angegeben wurde, mit Pepsinsalzsänre oder mit Pancreatin nach schwacher Alkalisirung. In dem einen wie anderen Falle erhalten wir eine Milch, in der bei richtiger Behandlung $82 \%$ $85 \%$ des Proteïn, oder gar noch mehr in Pepton übergeführt ist. Die durch Pancreatin peptonisirte Milch ist etwas gelblicher, als die durch Pepsinsalzsäure peptonisirte. Diese, wie jene, wird durch verdünnte Salzsäure nicht mehr dicklich coagulirt und ist, wie dies auch Versuche an Kranken herausgestellt haben, sehr leicht verdaulich. Aber der Verwendung steht doch ein nicht geringes Hinderniss entgegen. Die peptonisirte Milch hat nämlich nicht den angenehmen Geschmack der frisehen Milch, ist fade und bitter, besonders, wenigstens nach meinen Versuchen, die mit Pan-

1) Alexander Schmidt und Hammarsten, siehe Jahresbericht über die Fortschritte der Thierchemie. 1877. S. 163 und Arch. f. Phys. XI. S. $1 \mathrm{ff}$. 
creatin hergestellte. Zusatz von Zucker vermag allerdings den Geschmack zu bessern, ist aber in der Menge, in welcher er zu solchem Zwecke beigemischt werden muss, der Regel nach nicht zulässig. Frühzeitiges Abbrechen der Verdauung ${ }^{2}$ ) kann den bitteren Geschmack verbitten, aber dann bleibt eben noch ein grosser Theil des Proteïn unpeptonisirt. Will man nichts weiter, als partielle Ueberführung des Proteïn in Pepton, so bedient man sich noch zweckmässiger der oben angegebenen Methode des vierundzwanzigstiindigen Hinstellens der mit verdünnter Salzsäure versetzten Milch, die damn wenigstens keinen unangenehmen Geschmack annimmt.

Nach allem Diesem haben wir vor der Hand im Wesentlichen keine anderen Mittel, die Verdaulichkeit der Kuhmilch zu erhöhen, als diejenigen, welche eine Verkleinerung der bei der Einwirkung: des Verdauungssaftes entstehenden, Gerinnsel bedingen. Dass solche Mittel das Kuhmilcheaseïn dem Menschenmilchcaseïn nicht ähnlicher machen, ist freilich wahr; dass sie trotzdem die Verdaulichkeit der Kuhmilch verbessern, wird nach den hier mitgetheilten Versuchen gleichfalls als thatsächlich behauptet werden dürfen. - Von den Methoden aber, welche das Kuhmilchcaseïn dem Menschenmilchcasein in seinem Verhalten zum Magensafte ähnlicher machen, dürfte zur Zeit für die Praxis Beachtung nur die finden, nach welcher man Milch mit $2 \%$ Salzsäure im Verhältniss wie $7,5: 10 \mathrm{ccm}$, oder mit 4\% Salzäüure im Verhältniss, wie $7: 5 \mathrm{ccm}$ in der Weise mischt, dass man die Milch langsam unter Schuitteln in die Säurelösung eingiesst. Diese Methode ist auf Seite 24 und 25 der vorliegenden Abhandlung ausführlich besprochen worden.

Nachschrift: Die Arbeiten von Sehmidt-Mülheim und Hryntsehak sind mir erst nach Fertigstellung meiner Abhandlung bekannt geworden, konnten demnach nicht mebr berïcksichtigt werden.

1) Vergl. Pfeiffer's Besprechung der peptonisirten Milch in dem Bericht über die Verhandlungen der pädiatr. Section der 54. Versammlung deutscher Aerzte und Naturforscher. 